Article

\title{
Hybridization of Nanodiamond and CuFe-LDH as Heterogeneous Photoactivator for Visible-Light Driven Photo-Fenton Reaction: Photocatalytic Activity and Mechanism
}

\author{
Lu Liu ${ }^{1}$, Shijun $\mathrm{Li}^{2}$, Yonglei An ${ }^{2, *}$, Xiaochen Sun ${ }^{1}$, Honglin $\mathrm{Wu}^{2}{ }^{2}$, Junzhi Li ${ }^{1}$, Xue Chen ${ }^{2}$ and \\ Hongdong $\mathrm{Li}^{1 \text {,* }}$ \\ 1 State Key Laboratory of Superhard Materials, College of Physics, Jilin University, Changchun 130012, China; \\ liulu15@mails.jlu.edu.cn (L.L.); xcsun17@mails.jlu.edu.cn (X.S.); lijz17@mails.jlu.edu.cn (J.L.) \\ 2 Key Laboratory of Groundwater Resources and Environment (Jilin University), Ministry of Education, \\ Changchun 130021, China; lisj2516@mails.jlu.edu.cn (S.L.); wuhl2516@mails.jlu.edu.cn (H.W.); \\ chenxue2515@mails.jlu.edu.cn (X.C.) \\ * $\quad$ Correspondence: anyonglei85@jlu.edu.cn (Y.A.); hdli@jlu.edu.cn (H.L.)
}

Received: 26 December 2018; Accepted: 25 January 2019; Published: 29 January 2019

\begin{abstract}
Establishing a heterojunction for two kinds of semiconductor catalysts is a promising way to enhance photocatalytic activity. In this study, nanodiamond (ND) and CuFe-layered double hydroxide (LDH) were hybridized by a simple coprecipitation method as a novel heterojunction to photoactivate $\mathrm{H}_{2} \mathrm{O}_{2}$. The ND/LDH possessed a hydrotalcite-like structure, large specific surface area $\left(\mathrm{S}_{\mathrm{BET}}=99.16 \mathrm{~m}^{2} / \mathrm{g}\right)$, strong absorption of visible-light and low band gap $\left(\mathrm{E}_{\mathrm{g}}=0.94 \mathrm{eV}\right)$. Under the conditions of $\mathrm{ND} / \mathrm{LDH}$ dosage $0.0667 \mathrm{~g} / \mathrm{L}, \mathrm{H}_{2} \mathrm{O}_{2}$ concentration $19.6 \mathrm{mmol} / \mathrm{L}$, and without initial $\mathrm{pH}$ adjustment, $93.5 \%$ of $10 \mathrm{mg} / \mathrm{L}$ methylene blue (MB) was degraded within $120 \mathrm{~min}$, while only $78.3 \%$ of $\mathrm{MB}$ was degraded in the presence of $\mathrm{LDH}$ instead of ND/LDH. The ND/LDH exhibited excellent stability and maintained relatively high activity, sufficient to photoactivate $\mathrm{H}_{2} \mathrm{O}_{2}$ even after five recycles. The mechanism study revealed that in the heterojunction of ND/LDH, the photoelectrons transferred from the valence band of $\mathrm{LDH}\left(\mathrm{Cu} / \mathrm{Fe} 3 \mathrm{~d} \mathrm{t}_{2 \mathrm{~g}}\right)$ to the conduction band of $\mathrm{LDH}(\mathrm{Cu} / \mathrm{Fe}$ $3 \mathrm{~d} \mathrm{e}_{\mathrm{g}}$ ) could spontaneously migrate onto the conduction band of ND, promoting the separation of photo-induced charges. Thus, the photoelectrons had sufficient time to accelerate the redox cycles of $\mathrm{Cu}^{3+} / \mathrm{Cu}^{2+}$ and $\mathrm{Fe}^{3+} / \mathrm{Fe}^{2+}$ to photoactivate $\mathrm{H}_{2} \mathrm{O}_{2}$ to produce hydroxyl radicals, resulting in excellent photo-Fenton efficiency on MB degradation.
\end{abstract}

Keywords: heterojunction; layered double hydroxide; nanodiamond; photo-Fenton

\section{Introduction}

Water pollution with synthetic organics (e.g., dyes, pesticides, pharmaceuticals) is a worldwide problem because these unnatural organic pollutants are difficult to degrade with traditional chemical or biochemical processes [1,2]. Fortunately, advanced oxidation processes (AOPs) possess excellent oxidizing abilities for decomposing refractory organic pollutants, due to the oxidation of highly active radicals such as hydroxyl radical (HO.) [3-6]. As a typical AOP, Fenton technology is a simple and effective method for treating organic wastewater $[7,8]$. However, the leaching problem of catalysts (e.g., copper ion, iron ion) limits the application of Fenton technology [7-10]. In addition, the Fenton assisted by photoirradiation (photo-Fenton) is more efficient than the traditional Fenton [11,12]. Therefore, improving the utilization efficiency of visible-light is vital for the photo-Fenton because it can make full use of solar-light in which visible-light is absolutely dominant $[3,13]$. 
In recent years, layered double hydroxide (LDH) has been widely used as a catalyst carrier, or precursor, owing to its specific physicochemical properties which arises from its exchangeable metal cations and interlayer anions $[14,15]$. In general, LDH possesses such low band-gap energy $\left(E_{g}\right)$ that LDH can be easily excited by UV-Vis light. Thus, the photoelectrons of LDH would be captured by other chemicals to participate in reduction reactions, for example, water reduction and photocatalytic degradation [16-18]. More importantly, LDH can be reused as a heterogeneous catalyst and will not cause catalyst leakage and secondary metallic pollution $[19,20]$. In addition, copper ions and iron ions are two typical and efficient active-species for catalyzing the Fenton reaction $[7,21]$. Therefore, we set out to synthesize a stable and efficient $\mathrm{LDH}$ catalyst through doping $\mathrm{Cu}^{2+}$ and $\mathrm{Fe}^{3+}$ to catalyze the photo-Fenton reaction because there have been no reports of utilizing CuFe-LDH as a photo-Fenton catalyst.

As is commonly known, co-catalysis and element doping are both efficient ways of enhancing the photocatalytic activity of semiconductor photocatalysts [22]. Typically, co-catalysis is conducted through establishing a heterojunction which is effective for promoting the separation of photoexcitons (electron and hole) [22]. In recent years, nanodiamond (ND) has often been hybridized with other semiconductor photocatalysts to form heterojunctions for enhancing photocatalysis, due to its special physicochemical and optical properties and harmlessness to living organisms [23-26]. For example, the hybridization of $\mathrm{ND}$ and $\mathrm{TiO}_{2}$ was used to photodegrade organic pollutants $[27,28]$, the hybridization of $\mathrm{ND}$ and $\mathrm{Cu}_{2} \mathrm{O}$ was used for photocatalytic hydrogen evolution [23], and the hybridization of ND and gold was used to photocatalyze the Fenton reaction [29-31]. Indeed, the unrivalled carrier mobility and large specific surface area of ND may facilitate the transfer of photogenerated carriers to the photocatalyst surface $[23,32]$. However, these reactions were all conducted under UV-light or solar-light ( $7 \%$ is UV-light) irradiation [1]. If the photocatalysis on a ND heterojunction can be effectively driven by visible-light, it would be of great significance for the improvement of solar energy utilization.

Herein, a novel heterojunction hybridized by ND and CuFe-LDH was synthesized as a high-efficiency heterogeneous photo-Fenton catalyst. The crystal structure was characterized by high-resolution transmission electron microscopy (HRTEM) and X-ray diffraction (XRD), and the electronic structure was analyzed by X-ray photoelectron spectra (XPS) and UV-Vis diffuse reflectance spectra (DRS). Furthermore, the photocatalytic performance and mechanism of ND/LDH in the photo-Fenton reaction system were investigated in detail in this study.

\section{Results and Discussion}

\subsection{Characterization of $\mathrm{ND} / \mathrm{LDH}$}

HRTEM images of LDH and ND/LDH are shown in Figure 1. Four kinds of lattice fringes for bare LDH were clearly found in Figure 1B; the lattice fringe spacings were $0.243,0.233,0.217$ and $0.136 \mathrm{~nm}$, corresponding to (104), (015) crystal planes of the LDH phase referred to on PDF card No. 89-461 and (114), (209) crystal planes of LDH phase referred to on PDF card No. 87-1138, respectively. For $\mathrm{ND} / \mathrm{LDH}$, four typical lattice fringes were also clearly found in Figure 1D; the lattice fringe spacings were $0.243,0.233,0.205$ and $0.136 \mathrm{~nm}$, with $0.205 \mathrm{~nm}$ corresponding to the (111) crystal plane of cubic diamonds [33]. These results suggested that the as-prepared ND/LDH possessed a hydrotalcite-like structure, and that the ND was hybridized with LDH successfully. Moreover, the clear lattice fringes indicated good crystallinity of ND/LDH. 


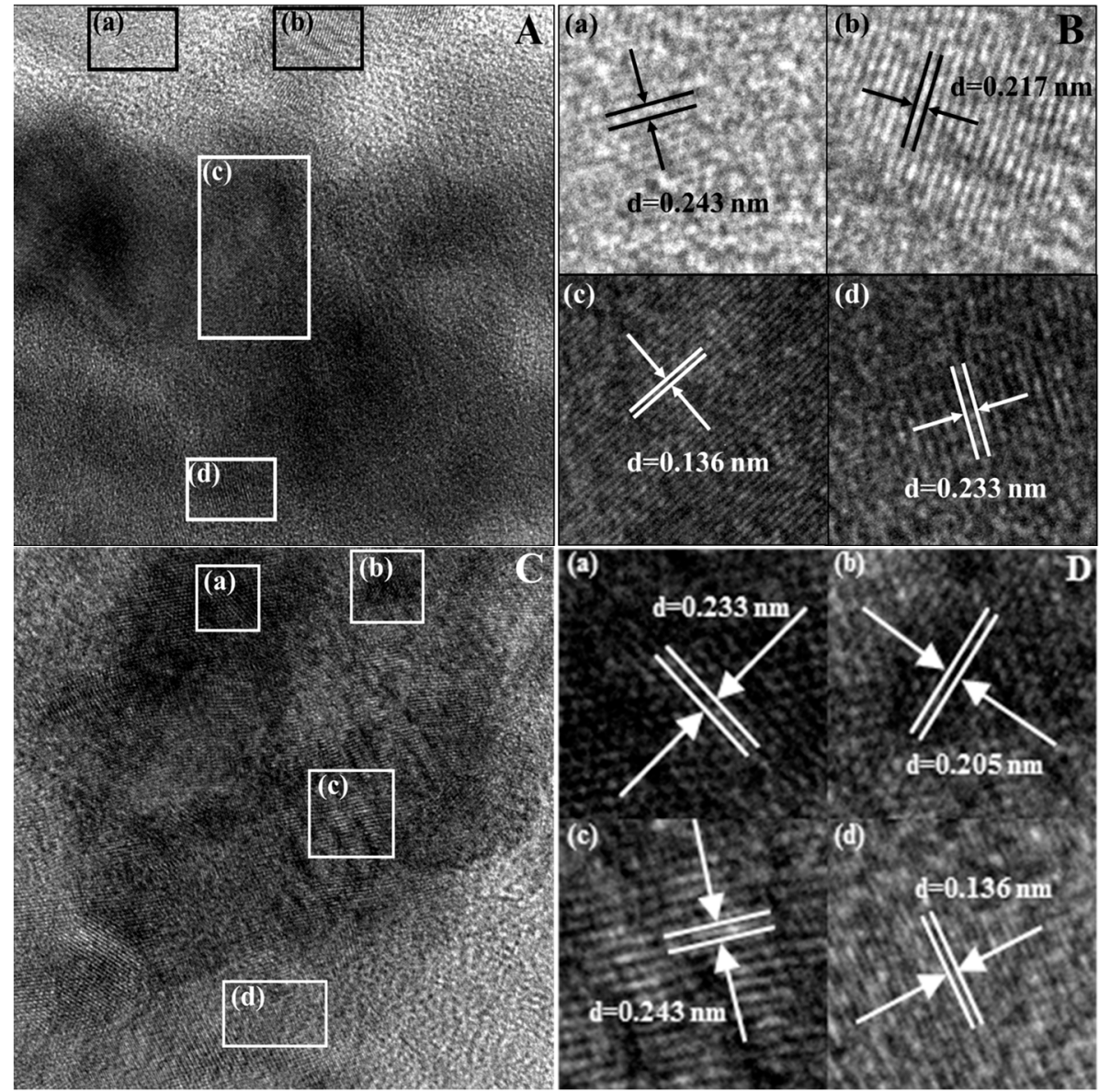

Figure 1. High-resolution transmission electron microscopy (HRTEM) images of layered double hydroxide $(\mathrm{LDH})(\mathbf{A}, \mathbf{B})$ and nanodiamond/layered double hydroxide (ND/LDH) $(\mathbf{C}, \mathbf{D})$. (a-d) are the four kinds of selected lattice fringes for $\mathrm{LDH}$ and ND/LDH, respectively.

The crystal phase and crystallinity of ND, LDH and ND/LDH were characterized using an X-ray diffractometer with $\mathrm{Cu} \mathrm{K} \alpha$ radiation over a range of $2 \theta$ angles from 20 to $90^{\circ}$ (Figure 2), respectively. Two representative diffraction peaks located at 44.66 and $78.08^{\circ}$ were observed in the ND spectrum, corresponding to the (111) and (220) crystal planes of diamond [33,34]. Two other diffraction peaks located at 38.62 and $64.98^{\circ}$ were also observed, corresponding to the (021) and (311) crystal planes of graphite phase referred to in PDF card No. 89-8488, and indicative of partial graphitization on the surface of ND. In the LDH spectrum, the $2 \theta$ of diffraction peaks were located at $32.10,33.28,35.90$, $39.24,44.66,64.98$ and $78.08^{\circ}$, corresponding to the (101), (009), (012), (015), (018), (116) and (1016) crystal planes of the LDH phase referred to in PDF card No. 89-461 and in the literature [35-37]. The remaining two outstanding diffraction peaks were located at 29.62 and $48.58^{\circ}$, corresponding to (005) and (107) crystal planes of the LDH phase referred to in PDF card No. 87-1138. For ND/LDH, all the diffraction peaks of ND and LDH were observed correspondingly, whereas the diffraction peaks of ND coincided with the partial peaks of LDH. In addition, a new diffraction peak at $22.96^{\circ}$ corresponding to the (006) crystal plane of LDH phase was detected in the ND/LDH spectrum [35-37]. These results adequately confirmed the hydrotalcite-like structure of ND/LDH and the successful hybridization of ND and LDH. Moreover, the sharp diffraction peaks indicated good crystallinity of ND/LDH. 


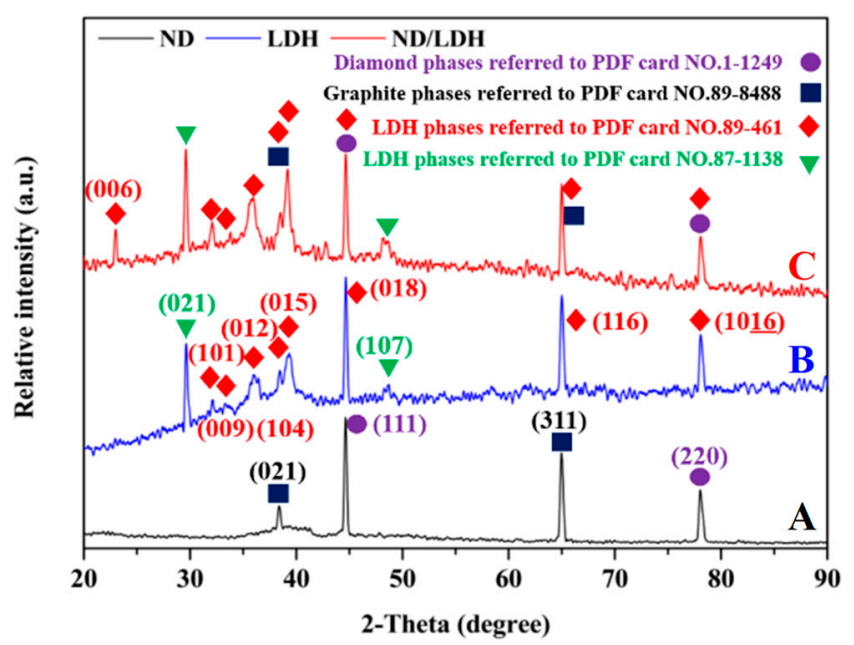

Figure 2. X-ray diffraction (XRD) spectra of ND (A), LDH (B) and ND/LDH (C).

The surface state of ND/LDH was investigated with the XPS method. The full-range XPS spectra is represented in Figure 3a, where peaks corresponding to $\mathrm{C} 1 \mathrm{~s}, \mathrm{Cu} 2 \mathrm{p}$ and Fe $2 \mathrm{p}$ were detected. The sharp peak of $C 1 \mathrm{~s}$ was composed of four splitting peaks at 284.39, 284.96, 286.06 and $287.83 \mathrm{eV}$ (Figure 3b). $284.96 \mathrm{eV}$ suggested sp3-hybridized carbon, indicating the existence of ND. $284.39 \mathrm{eV}$ suggested sp2-hybridized carbon, indicating partial graphitization on the surface of ND, which was consistent with the XRD results. 286.06 and $287.83 \mathrm{eV}$ suggested $\mathrm{C}-\mathrm{O}$ and $\mathrm{C}=\mathrm{O}$ structures, respectively, attributed to the oxygen-containing groups on the surface of $\mathrm{ND}$ [38]. For $\mathrm{Cu} 2 \mathrm{p}$ (Figure 3c), two typical peaks were located at 954.62 and $934.64 \mathrm{eV}$, corresponding to $\mathrm{Cu} 2 \mathrm{p}_{1 / 2}$ and $\mathrm{Cu} 2 \mathrm{p}_{3 / 2}$. Correspondingly, the other two peaks, at 942.68 and $962.75 \mathrm{eV}$, were the satellite peaks of $\mathrm{Cu} 2 \mathrm{p}$. These results suggest that the copper in ND/LDH appeared as $\mathrm{Cu}^{2+}$ with the outermost electron configuration of $3 \mathrm{~d}^{9}$ [39-42]. For Fe $2 p$ (Figure 3d), the XPS peak of Fe $2 p_{1 / 2}$ was located at $724.69 \mathrm{eV}$, and the peak of Fe $2 p_{3 / 2}$ was composed of two splitting peaks at 711.38 and $714.05 \mathrm{eV}$, indicating that iron in ND/LDH appeared as $\mathrm{Fe}^{3+}$ with the outermost electron configuration of $3 \mathrm{~d}^{5}[5,43]$. 

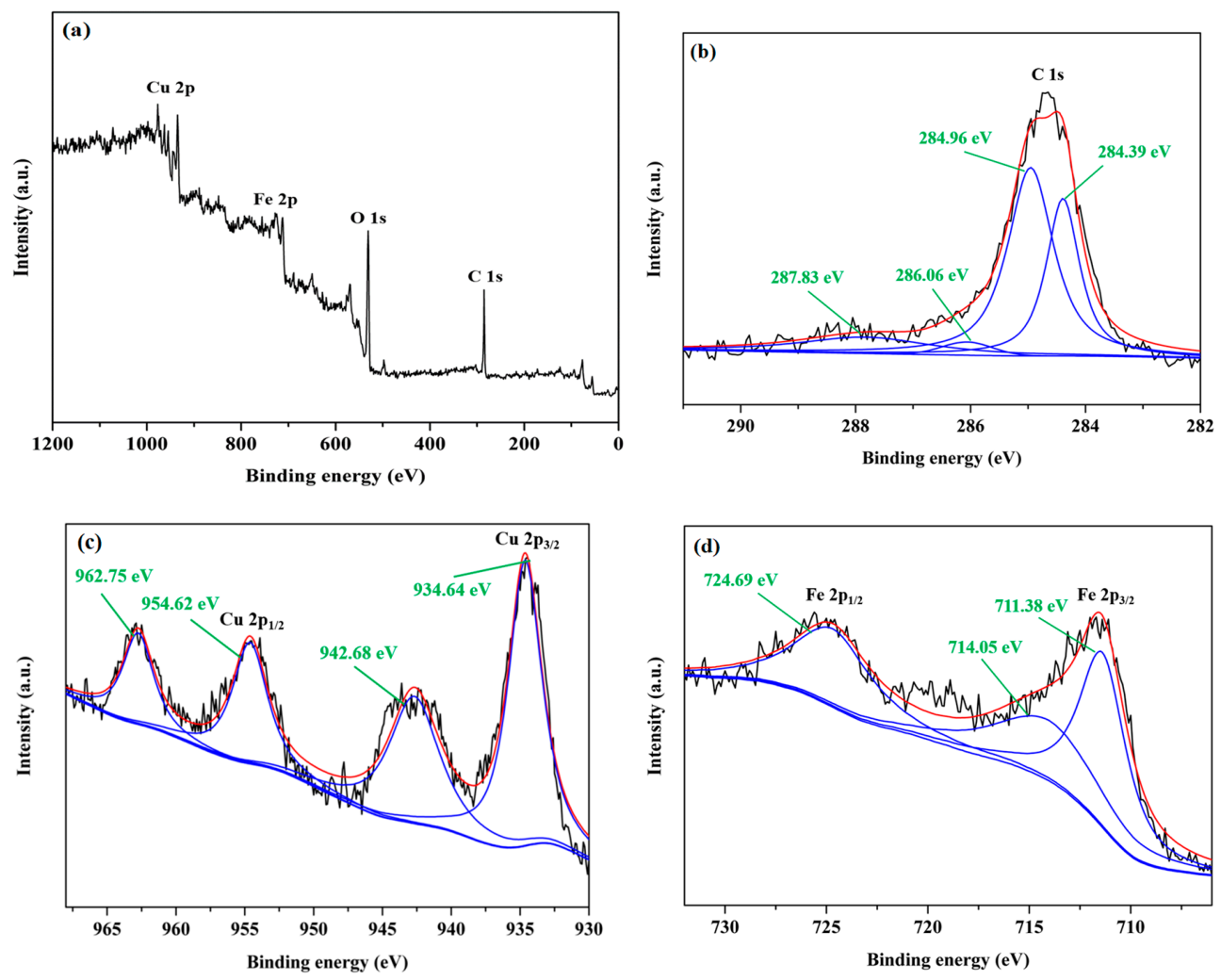

Figure 3. (a) Full-range X-ray photoelectron spectra (XPS) spectra of ND/LDH; (b) XPS peaks for C 1s; (c) XPS peaks for Cu 2p; (d) XPS peaks for Fe 2p.

FTIR spectra of $\mathrm{LDH}$ and ND/LDH were recorded using $\mathrm{KBr}$ pellets and the results are presented in Figure 4. The sharp peak at $3422 \mathrm{~cm}^{-1}$ was ascribed to the stretching vibration of hydroxyl, which would come from the metal layer of LDH or ND [33]. A carbon dioxide absorption peak was also found at $2373 \mathrm{~cm}^{-1}$. The peak at $1637 \mathrm{~cm}^{-1}$ was ascribed to the bending vibration of hydroxyl which is located at the interlayer of LDH or ND [33]. The peak at $1385 \mathrm{~cm}^{-1}$ was ascribed to the stretching vibration of the $\mathrm{C}-\mathrm{O}$ structure which was from the carbonate located in the anionic interlayer of $\mathrm{LDH}$, or from the oxygen-containing group on the ND surface. The peaks at 1050 and $505 \mathrm{~cm}^{-1}$ were ascribed to $\mathrm{Cu}-\mathrm{O}-\mathrm{Fe}$ stretching vibration and metallic bond vibration $(\mathrm{M}-\mathrm{OH})$, respectively $[1,37,44]$. These results also indicated that the as-prepared ND/LDH possessed a hydrotalcite-like structure, and the copper and iron atoms in the metal layer were connected by an oxygen atom. Moreover, these results indicated that ND and LDH were hybridized successfully.

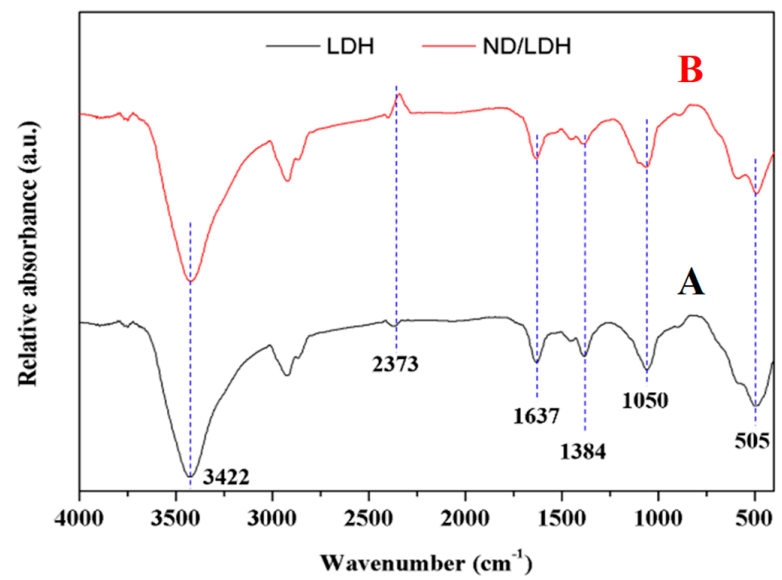

Figure 4. Fourier transform infrared (FTIR) spectra of LDH (A) and ND/LDH (B). 
The surface area and pore structure of $\mathrm{LDH}$ and $\mathrm{ND} / \mathrm{LDH}$ were investigated by the $\mathrm{N}_{2}$ adsorption-desorption isotherm, respectively (Figure 5). Both LDH and ND/LDH exhibited typical IV isotherms with H3-type hysteresis loops $\left(\mathrm{P} / \mathrm{P}_{0}>0.4\right)$, indicating the presence of mesopores [35]. Furthermore, no limiting adsorption at higher $\mathrm{P} / \mathrm{P}_{0}$ was observed, indicative of the existence of macropores [45]. The Brunauer-Emmett-Teller (BET) surface area of ND/LDH (S clearly higher than that of $\mathrm{LDH}\left(\mathrm{S}_{\mathrm{BET}}=63.62 \mathrm{~m}^{2} / \mathrm{g}\right)$, which would facilitate the photocatalytic activity of ND/LDH. Additionally, pore size distributions were determined using the Barrett-Joyner-Halenda (BJH) method. As is shown in Figure $5 b, d, 2-20 \mathrm{~nm}$ was observed as the main pore size for both $\mathrm{LDH}$ and $\mathrm{ND} / \mathrm{LDH}$, indicating that the as-prepared $\mathrm{ND} / \mathrm{LDH}$ belonged as a mesoporous material. Therefore, it can be inferred that ND/LDH, rather than bare LDH, would possess excellent catalytic activity due to its mesoporous structure and higher surface area.
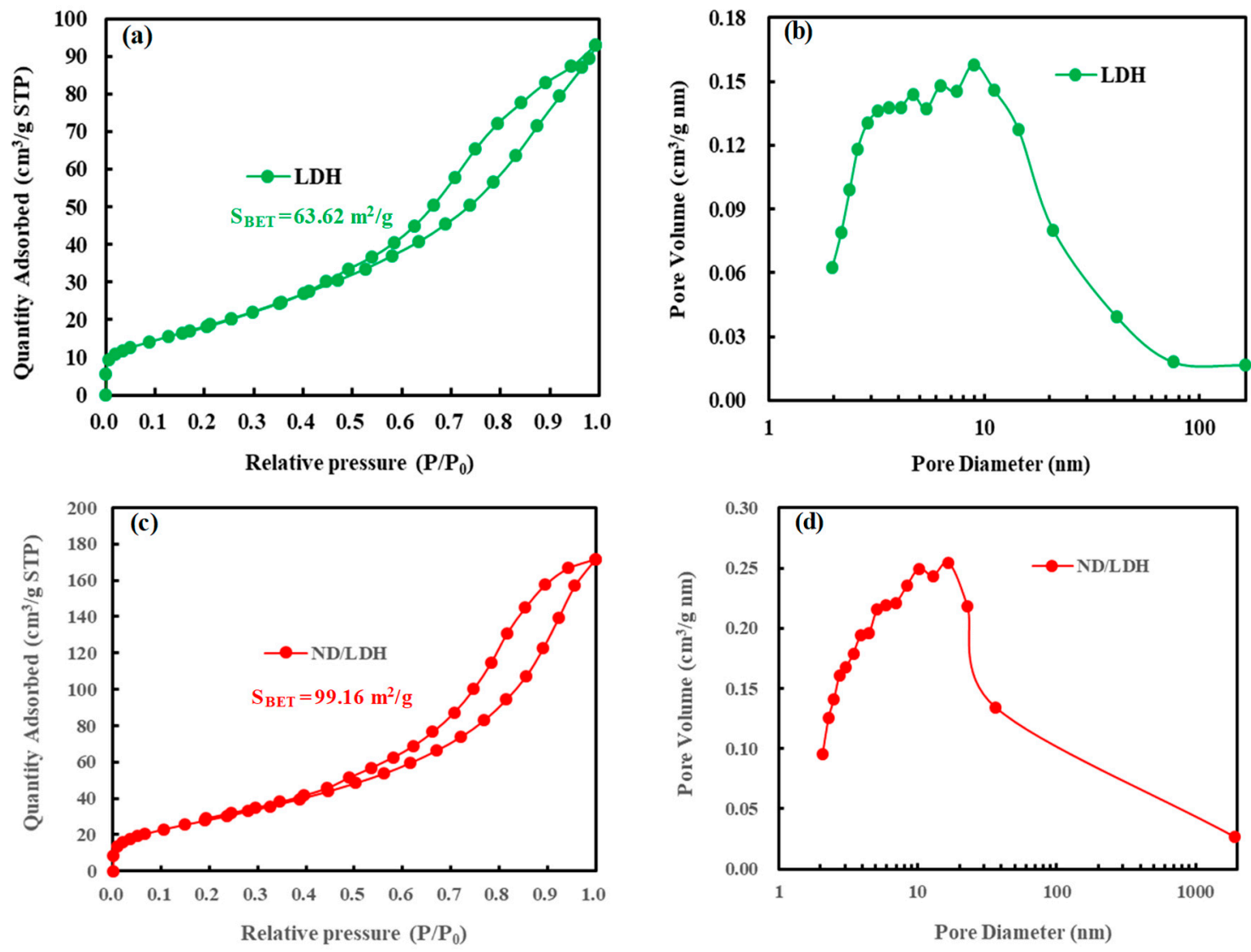

Figure 5. (a) Nitrogen adsorption-desorption isotherm of LDH; (b) Pore diameter distribution curve of $\mathrm{LDH}$; (c) Nitrogen adsorption-desorption isotherm of ND/LDH; (d) Pore diameter distribution curve of $\mathrm{ND} / \mathrm{LDH}$.

\subsection{Photocatalytic Activity of ND/LDH}

In order to investigate the photocatalytic activities of ND/LDH under visible-light irradiation, methylene blue (MB) dye was employed as the targeted pollutant. As shown in Figure 6, in a dark environment (Figure 6a), both LDH and ND/LDH had no removal effectiveness on MB, indicating no absorption of $\mathrm{MB}$ on $\mathrm{LDH}$ or ND/LDH. Bare $\mathrm{H}_{2} \mathrm{O}_{2}$ had a little removal effectiveness on $\mathrm{MB}$ in darkness, which would be ascribed to its intrinsic oxidability. However, the assembly of LDH combined with $\mathrm{H}_{2} \mathrm{O}_{2}\left(\mathrm{LDH} / \mathrm{H}_{2} \mathrm{O}_{2}\right.$ ) demonstrated high activity on $\mathrm{MB}$ removal in darkness and the removal rate of $\mathrm{MB}$ at $120 \mathrm{~min}$ reached $36.7 \%$. Meanwhile, $\mathrm{ND} / \mathrm{LDH} / \mathrm{H}_{2} \mathrm{O}_{2}$ demonstrated slightly higher activity on $\mathrm{MB}$ removal in darkness and the removal rate of $\mathrm{MB}$ at 120 min reached $38.4 \%$. 
When the Fenton reaction systems were irradiated by visible-light (Figure 6c), both LDH and $\mathrm{ND} / \mathrm{LDH}$ still had no removal effectiveness on $\mathrm{MB}$, while bare $\mathrm{H}_{2} \mathrm{O}_{2}$ showed better $\mathrm{MB}$ removal than in darkness. To our excitement, both $\mathrm{LDH} / \mathrm{H}_{2} \mathrm{O}_{2}$ and $\mathrm{ND} / \mathrm{LDH} / \mathrm{H}_{2} \mathrm{O}_{2}$ demonstrated dramatically higher activity on $\mathrm{MB}$ removal under visible-light irradiation than in darkness, and the removal rate of $\mathrm{MB}$ at $120 \mathrm{~min}$ reached $78.3 \%$ and $93.5 \%$, respectively. The kinetics of MB degradation were also investigated. The experimental data were fitted with the pseudo-first-order kinetic equation as expressed by Equation (18). The results clearly showed that the apparent rate constant $(k)$ of $\mathrm{ND} / \mathrm{LDH} / \mathrm{H}_{2} \mathrm{O}_{2}$ for $\mathrm{MB}$ degradation under visible-light irradiation $\left(23.3 \times 10^{-3} \mathrm{~min}^{-1}\right)$ was higher than that of $\mathrm{LDH} / \mathrm{H}_{2} \mathrm{O}_{2}\left(12.9 \times 10^{-3} \mathrm{~min}^{-1}\right)$ (Table 1). These results demonstrated that the hybridization of $\mathrm{ND} / \mathrm{LDH}$, rather than bare $\mathrm{LDH}$, positively improved the efficiency of the visible-light driven photo-Fenton $(\lambda \geq 420 \mathrm{~nm})$.
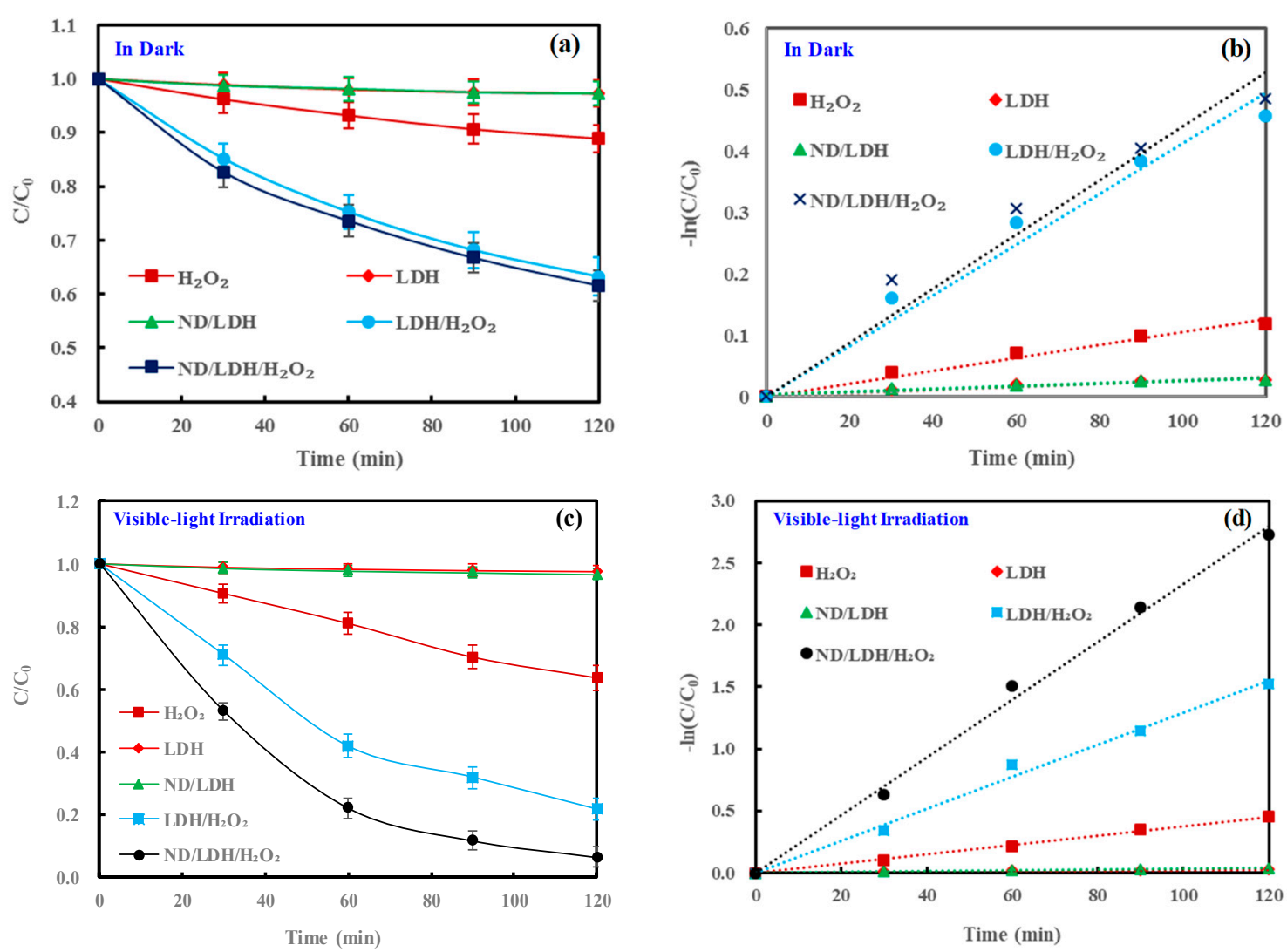

Figure 6. (a) Degradation of methylene blue (MB) in darkness; (b) pseudo-first-order kinetic fit for MB degradation in darkness; (c) photocatalytic degradation of MB under visible-light irradiation; and (d), pseudo-first-order kinetic fit for MB photodegradation under visible-light irradiation. (Error bars represent standard deviation of triplicate runs).

Many studies in the literature have reported that the concentration of a heterogeneous photocatalyst had a dramatic impact on photocatalytic efficiency [46]. Thus, the effects of ND/LDH dosage on $\mathrm{MB}$ removal under visible-light irradiation were investigated, with a concentration range of $\mathrm{ND} / \mathrm{LDH}$ from 0.0027 to $0.2667 \mathrm{~g} / \mathrm{L}$. Clearly, $0.0667 \mathrm{~g} / \mathrm{L}$ was the optimal concentration for ND/LDH to photocatalytically degrade $\mathrm{MB}$ dye (Figure 7), and the corresponding apparent rate constant $(k)$ was the highest $\left(23.3 \times 10^{-3} \mathrm{~min}^{-1}\right)$ (Table 1$)$. It should be noted that the turbidity of the reaction solution gradually increased, along with the increase in the ND/LDH dosage. Excessive high-turbidity can weaken the light penetrating into a photocatalytic solution, resulting in low photocatalytic efficiency [46]. 

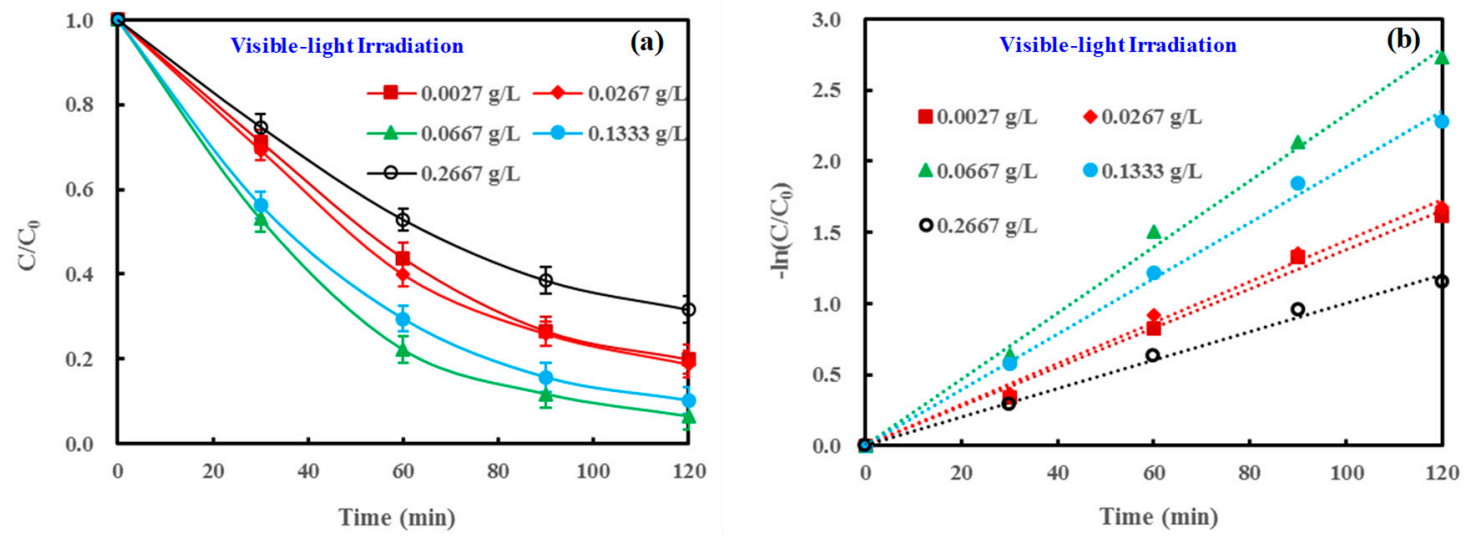

Figure 7. (a) Effect of $\mathrm{ND} / \mathrm{LDH}$ dosage on $\mathrm{MB}$ removal under visible-light irradiation; and (b) pseudo-first-order kinetic fit for MB removal. (Error bars represent standard deviation of triplicate runs).

Table 1. Pseudo-first-order rate constants $(k)$ of $\mathrm{MB}$ degradation and respective regression coefficients ( $r 2)$ in different reaction systems.

\begin{tabular}{|c|c|c|c|c|c|}
\hline $\begin{array}{c}\text { Photocatalytic } \\
\text { Reagents }\end{array}$ & $\begin{array}{l}\text { Dosage of LDH or } \\
\text { ND/LDH (g/L) }\end{array}$ & $\begin{array}{l}\text { Dosage of Radical } \\
\text { Scavenger }\end{array}$ & $\begin{array}{l}\text { Irradiation } \\
\text { Condition }\end{array}$ & $k\left(10^{-3} \min ^{-1}\right)$ & $r 2$ \\
\hline $\mathrm{H}_{2} \mathrm{O}_{2}$ & - & - & In dark & 0.1 & 0.9786 \\
\hline $\mathrm{H}_{2} \mathrm{O}_{2}$ & - & - & VLI & 3.8 & 0.9955 \\
\hline $\mathrm{LDH}$ & 0.0667 & - & In dark & 0.2 & 0.9388 \\
\hline $\mathrm{LDH}$ & 0.0667 & - & VLI & 0.2 & 09012 \\
\hline $\mathrm{ND} / \mathrm{LDH}$ & 0.0667 & - & In dark & 0.3 & 0.9105 \\
\hline ND/LDH & 0.0667 & - & VLI & 0.3 & 0.9199 \\
\hline $\mathrm{LDH} / \mathrm{H}_{2} \mathrm{O}_{2}$ & 0.0667 & - & In dark & 4.1 & 0.9685 \\
\hline $\mathrm{LDH} / \mathrm{H}_{2} \mathrm{O}_{2}$ & 0.0667 & - & VLI & 12.9 & 0.9918 \\
\hline $\mathrm{ND} / \mathrm{LDH} / \mathrm{H}_{2} \mathrm{O}_{2}$ & 0.0667 & - & In dark & 4.4 & 0.9507 \\
\hline $\mathrm{ND} / \mathrm{LDH} / \mathrm{H}_{2} \mathrm{O}_{2}$ & 0.0667 & - & VLI & 23.3 & 0.9955 \\
\hline $\mathrm{ND} / \mathrm{LDH} / \mathrm{H}_{2} \mathrm{O}_{2}$ & 0.0027 & - & VLI & 13.8 & 0.9919 \\
\hline $\mathrm{ND} / \mathrm{LDH} / \mathrm{H}_{2} \mathrm{O}_{2}$ & 0.0267 & - & VLI & 14.4 & 0.9931 \\
\hline $\mathrm{ND} / \mathrm{LDH} / \mathrm{H}_{2} \mathrm{O}_{2}$ & 0.1333 & - & VLI & 19.6 & 0.9956 \\
\hline $\mathrm{ND} / \mathrm{LDH} / \mathrm{H}_{2} \mathrm{O}_{2}$ & 0.2667 & - & VLI & 10.0 & 0.9924 \\
\hline $\mathrm{ND} / \mathrm{LDH} / \mathrm{H}_{2} \mathrm{O}_{2}$ & 0.0667 & $0.5 \mathrm{~mL} / \mathrm{L}$ of TBA & VLI & 19.3 & 0.9929 \\
\hline $\mathrm{ND} / \mathrm{LDH} / \mathrm{H}_{2} \mathrm{O}_{2}$ & 0.0667 & $2.0 \mathrm{~mL} / \mathrm{L}$ of $\mathrm{TBA}$ & VLI & 10.2 & 0.9850 \\
\hline $\mathrm{ND} / \mathrm{LDH} / \mathrm{H}_{2} \mathrm{O}_{2}$ & 0.0667 & $5.0 \mathrm{~mL} / \mathrm{L}$ of TBA & VLI & 3.5 & 0.9073 \\
\hline $\mathrm{ND} / \mathrm{LDH} / \mathrm{H}_{2} \mathrm{O}_{2}$ & 0.0667 & $0.5 \mathrm{~mL} / \mathrm{L}$ of $\mathrm{EtOH}$ & VLI & 12.3 & 0.9963 \\
\hline $\mathrm{ND} / \mathrm{LDH} / \mathrm{H}_{2} \mathrm{O}_{2}$ & 0.0667 & $2.0 \mathrm{~mL} / \mathrm{L}$ of $\mathrm{EtOH}$ & VLI & 5.5 & 0.9676 \\
\hline $\mathrm{ND} / \mathrm{LDH} / \mathrm{H}_{2} \mathrm{O}_{2}$ & 0.0667 & $5.0 \mathrm{~mL} / \mathrm{L}$ of $\mathrm{EtOH}$ & VLI & 1.0 & 0.9461 \\
\hline
\end{tabular}

The dosages of $\mathrm{H}_{2} \mathrm{O}_{2}$ were all $19.6 \mathrm{mmol} / \mathrm{L}$ in each reaction; VLI means visible-light irradiation.

The stability of the photocatalyst is also a pivotal factor during the catalytic process. In order to investigate the stability of $\mathrm{ND} / \mathrm{LDH}$, the previous sample was reused in the same experimental conditions. Figure 8 a represents the photocatalytic degradation cycle times of MB on ND/LDH. After five cycles, the degradation efficiency of $\mathrm{MB}$ on ND/LDH remained above $93.2 \%$, indicating high stability and photocatalytic activity of ND/LDH over repeated use. Additionally, the heavy metals, copper and iron, leaching from ND/LDH were investigated during the first use process. Figure $8 \mathrm{~b}$ shows that a little copper was leaching from ND/LDH, while no iron was detected throughout the whole photodegradation process. Although it has been reported that leakage of copper would reduce the redox cycle efficiency of $\mathrm{Cu}^{3+} / \mathrm{Cu}^{2+}[3,10]$, there was so little leakage of copper that this did not decrease the photocatalytic activity of ND/LDH. 

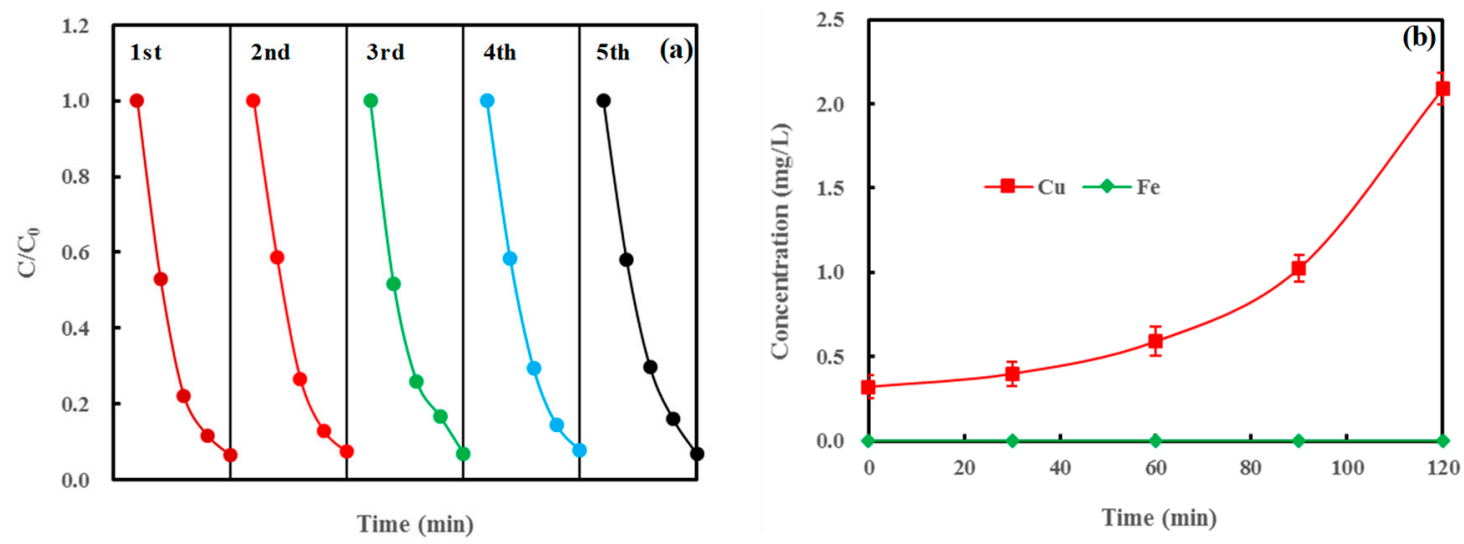

Figure 8. (a) Photocatalytic degradation cycle of $\mathrm{MB}$ on ND/LDH; and (b) leakage of $\mathrm{Cu}$ and Fe from $\mathrm{ND} / \mathrm{LDH}$ in the reaction solution. (Error bars represent standard deviation of triplicate runs).

\subsection{Photocatalytic Mechanism of ND/LDH}

It is an indisputable fact that the ND/LDH/ $\mathrm{H}_{2} \mathrm{O}_{2}$ irradiated by visible-light can enhance the photo-Fenton degradation of $\mathrm{MB}$ dye efficiently. To answer the question that there was specious decoloration or further mineralization for $\mathrm{MB}$, the total organic carbon (TOC) concentrations of the MB solution were monitored dynamically during the photodegradation process. The results in Figure 9 show that the TOC of the MB solution treated with $\mathrm{ND} / \mathrm{LDH} / \mathrm{H}_{2} \mathrm{O}_{2}$ with visible-light irradiation decreased regularly along with the reaction time, and the removal rate of TOC at 120 min was $89.7 \%$, a little lower than the removal rate of MB (93.5\%) quantified by decoloring degree (Figure 6). For other reported photo-Fenton catalysts, such as FePcS-LDH and CdS-carbon nanotube/ $\mathrm{TiO}_{2}$, the TOC removals of MB at the reaction time of 120 min were only $50.0 \%$ and $84.0 \%$, respectively $[47,48]$. These results confirmed that $\mathrm{MB}$ was positively mineralized in the $\mathrm{ND} / \mathrm{LDH} / \mathrm{H}_{2} \mathrm{O}_{2} /$ visible-light system, although there was a little residue of TOC, and that ND/LDH was more efficient than previously reported photo-Fenton catalysts for TOC removal.

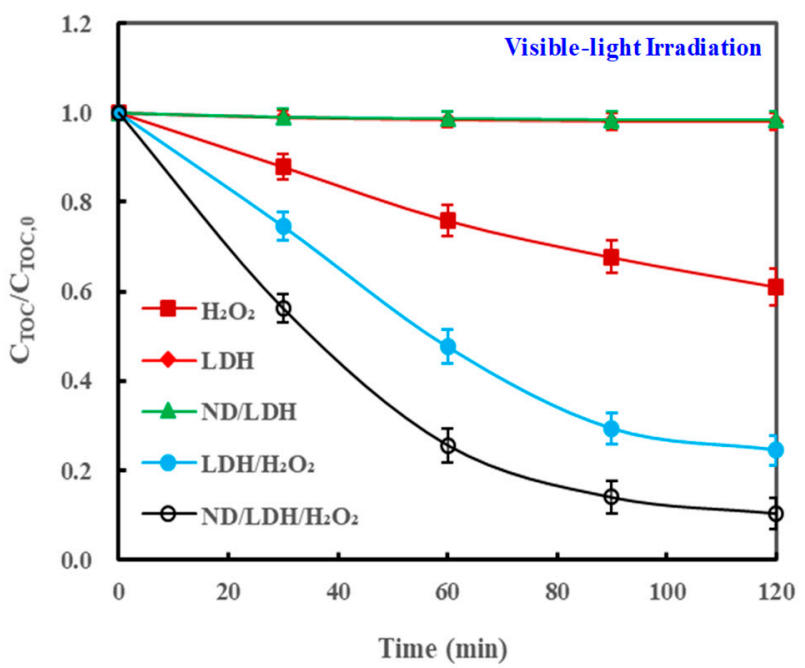

Figure 9. Variation of total organic carbon (TOC) of MB solution during the photodegradation process.

Generally, the mineralization of organic pollutants results from the oxidation of free radicals in AOPs. For the Fenton reaction, the hydroxyl radical is the main active-species for oxidizing the organic pollutant and leads to mineralization [6-8]. Hence, $t$-butanol (TBA) and absolute ethanol (EtOH) which are often used as hydroxyl radical scavengers, were employed to investigate the mechanism of ND/LDH/ $\mathrm{H}_{2} \mathrm{O}_{2} /$ visible-light treatment $[49,50]$. The results in Figure 10 clearly showed that both 
TBA and EtOH can inhibit the degradation of $\mathrm{MB}$, and the higher concentration of the scavengers was, the stronger the inhibition. Correspondingly, the apparent rate constant $(k)$ of MB degradation also declined dramatically with the increasing addition of hydroxyl radical scavengers (Table 1). Therefore, it was verified that the hydroxyl radical was the main active-species for MB degradation in the $\mathrm{ND} / \mathrm{LDH} / \mathrm{H}_{2} \mathrm{O}_{2} /$ visible-light system.
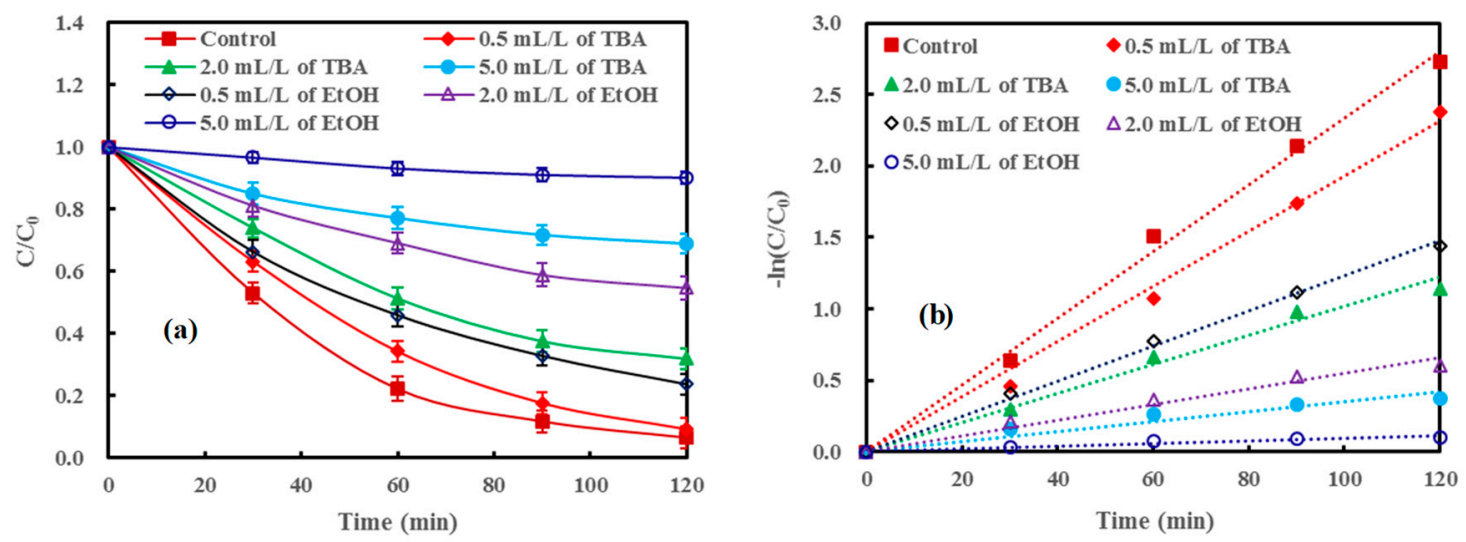

Figure 10. (a) Effect of free radical scavengers ( $t$-butanol, TBA; absolute ethanol, EtOH) on MB removal under visible-light irradiation; and (b) pseudo-first-order kinetic fit for MB removal. (Error bars represent standard deviation of triplicate runs).

The results of XPS indicated that bivalent copper and trivalent iron were the main elementary forms in ND/LDH (Figure 3). As is commonly known, the redox cycle of $\mathrm{Fe}^{3+} / \mathrm{Fe}^{2+}$ $\left(\mathrm{E}\left(\mathrm{Fe}^{3+} / \mathrm{Fe}^{2+}\right)=0.77 \mathrm{eV}\right.$ vs. NHE) is the fundamental driver for the traditional Fenton reaction [3]. It also had been reported that the redox cycle of $\mathrm{Cu}^{3+} / \mathrm{Cu}^{2+}\left(\mathrm{E}\left(\mathrm{Cu}^{3+} / \mathrm{Cu}^{2+}\right)=2.30 \mathrm{eV}\right.$ vs. NHE $)$ rather than $\mathrm{Cu}^{2+} / \mathrm{Cu}^{+}\left(\mathrm{E}\left(\mathrm{Cu}^{2+} / \mathrm{Cu}^{+}\right)=0.15 \mathrm{eV}\right.$ vs. $\left.\mathrm{NHE}\right)$ would more efficiently catalyze $\mathrm{H}_{2} \mathrm{O}_{2}$ to produce hydroxyl radicals, because such a reaction is thermodynamically feasible for activating $\mathrm{H}_{2} \mathrm{O}_{2}[6,10,21,22,51]$. Consequently, the redox cycles of $\mathrm{Cu}^{3+} / \mathrm{Cu}^{2+}, \mathrm{Cu}^{2+} / \mathrm{Cu}^{+}$and $\mathrm{Fe}^{3+} / \mathrm{Fe}^{2+}$ in $\mathrm{ND} / \mathrm{LDH}$ would synergistically catalyze $\mathrm{H}_{2} \mathrm{O}_{2}$ to produce hydroxyl radicals for $\mathrm{MB}$ degradation. The detailed reaction mechanism was described as follows [3,36,52]:

$$
\begin{gathered}
\mathrm{Cu}^{2+}+\mathrm{H}_{2} \mathrm{O}_{2} \rightarrow \mathrm{Cu}^{3+}+\mathrm{HO}+\mathrm{OH}^{-} \\
\mathrm{Fe}^{3+}+\mathrm{H}_{2} \mathrm{O}_{2} \rightarrow \mathrm{HO}_{2} \cdot+\mathrm{Fe}^{2+}+\mathrm{H}^{+} \\
\mathrm{Cu}^{3+}+\mathrm{H}_{2} \mathrm{O}_{2} \rightarrow \mathrm{Cu}^{2+}+\mathrm{HO}_{2}+\mathrm{H}^{+} \\
\mathrm{HO}_{2}+\mathrm{H}_{2} \mathrm{O}_{2} \rightarrow \mathrm{O}_{2}+\mathrm{H}_{2} \mathrm{O}+\mathrm{HO} \\
\mathrm{Cu}^{3+}+\mathrm{Fe}^{2+} \rightarrow \mathrm{Cu}^{2+}+\mathrm{Fe}^{3+} \\
\mathrm{Fe}^{2+}+\mathrm{H}_{2} \mathrm{O}_{2} \rightarrow \mathrm{Fe}^{3+}+\mathrm{HO} \cdot+\mathrm{OH}^{-} \\
\mathrm{Cu}^{2+}+\mathrm{H}_{2} \mathrm{O}_{2} \rightarrow \mathrm{Cu}^{+}+\mathrm{HO}_{2} \cdot+\mathrm{H}^{+} \\
\mathrm{Cu}^{+}+\mathrm{H}_{2} \mathrm{O}_{2} \rightarrow \mathrm{Cu}^{2+}+\mathrm{HO} \cdot+\mathrm{HO}^{-} \\
\mathrm{HO} \cdot+\mathrm{MB} \text { dye } \rightarrow \text { Degradation }
\end{gathered}
$$

When the Fenton reaction performed by ND/LDH/ $\mathrm{H}_{2} \mathrm{O}_{2}$ was irradiated by visible-light $(\lambda \geq 420 \mathrm{~nm})$, the removal rate of $\mathrm{MB}$ dramatically increased in the photo-Fenton reaction system (Figure 6). To investigate the photocatalytic mechanism, the optical properties of LDH and ND/LDH were determined by UV-Vis diffuse reflectance spectra (DRS) from 190 to $800 \mathrm{~nm}$. The results showed four strong absorption bands in the spectral regions, of 190-250 nm, 280-400 nm, 450-680 nm and 
770-800 nm, which can be attributed to the ligand-to-metal charge transfer (LMCT) that arises from the $2 p$ orbital of oxygen to the $3 \mathrm{~d}$ orbitals of $\mathrm{Cu} / \mathrm{Fe}$ (Figure 11a) [53-56]. Owing to the orbital split caused by crystal electric field action, the absorption band located at 190-250 $\mathrm{nm}$ should be ascribed to the electron transfer from $\sigma$ orbital of $\mathrm{O} 2 \mathrm{p}$ to $\sigma^{*}\left(\mathrm{e}_{\mathrm{g}}\right)$ orbital of $\mathrm{Cu} / \mathrm{Fe} 3 \mathrm{~d}$, the band located at $280-400 \mathrm{~nm}$ ascribed to the electron transfer from $\sigma$ orbital of $\mathrm{O} 2 \mathrm{p}$ to $\pi^{*}\left(\mathrm{t}_{2 \mathrm{~g}}\right)$ orbital of $\mathrm{Cu} / \mathrm{Fe} 3 \mathrm{~d}$, the band located at $450-680 \mathrm{~nm}$ ascribed to the electron transfer from $\pi$ orbital of $\mathrm{O} 2 \mathrm{p}$ to $\sigma^{*}\left(\mathrm{e}_{\mathrm{g}}\right)$ orbital or $\pi^{*}\left(\mathrm{t}_{2 \mathrm{~g}}\right)$ orbital of $\mathrm{Cu} / \mathrm{Fe} 3 \mathrm{~d}$, and the band located at $770-800 \mathrm{~nm}$ ascribed to the electron transfer from $\pi^{*}\left(\mathrm{t}_{2 \mathrm{~g}}\right)$ orbital to $\sigma^{*}\left(\mathrm{e}_{\mathrm{g}}\right)$ orbital of $\mathrm{Cu} / \mathrm{Fe} 3 \mathrm{~d}$ (d-d internal electron transition) [16]. These results demonstrated that both LDH and ND/LDH can absorb visible-light efficiently, suggesting small band gaps of LDH and $\mathrm{ND} / \mathrm{LDH}$, which were associated with the excellent photocatalytic performance on MB removal under visible-light irradiation. However, the absorbance curve of LDH declined consistently after $675 \mathrm{~nm}$, while the absorbance curve of ND/LDH began to decline at $770 \mathrm{~nm}$, suggesting that the band gap energy of ND/LDH $\left(\mathrm{E}_{\mathrm{g}}(\mathrm{ND} / \mathrm{LDH})\right)$ was smaller than the band gap energy of $\mathrm{LDH}\left(\mathrm{E}_{\mathrm{g}}(\mathrm{LDH})\right)$. Generally, the band gap energy of a crystalline semiconductor can be calculated from the following equation $[16,57,58]$ :

$$
(\alpha \times \mathrm{h} \times v)^{1 / \mathrm{n}}=\mathrm{A} \times(\mathrm{h} \times v-\mathrm{Eg})
$$

where $\alpha, h, v, E_{g}$ and A are the the absorption coefficient, Planck's constant, light frequency, band gap energy and a constant, respectively. Aside from these, $\mathrm{n}$ is determined by the type of optical transition of a semiconductor ( $n=1 / 2$ for direct transition and $n=2$ for indirect transition) [59]. LDHs have previously been found to have direct transitions [17]. Therefore, the plots of $(\alpha \times h \times v)^{2}$ versus $h \times v$ (Kubelka-Munk function as a function of light energy) gave the values of the band gap energy by extrapolating the straight line to the $h \times v$ axis intercept, as shown in Figure 11b. The estimated $\mathrm{E}_{\mathrm{g}}(\mathrm{LDH})$ was found to be $1.06 \mathrm{eV}$, suggesting a photoelectron transfer from $\mathrm{Cu} / \mathrm{Fe} 3 \mathrm{~d} \mathrm{t} \mathrm{t}_{\mathrm{g}}$ to $\mathrm{Cu} / \mathrm{Fe} 3 \mathrm{~d}$ $\mathrm{e}_{\mathrm{g}}$. However, the estimated $\mathrm{E}_{\mathrm{g}}(\mathrm{ND} / \mathrm{LDH})$ was found to be $0.94 \mathrm{eV}$, clearly lower than $\mathrm{E}_{\mathrm{g}}(\mathrm{LDH})$, which should arise from the hybridization of ND and LDH.
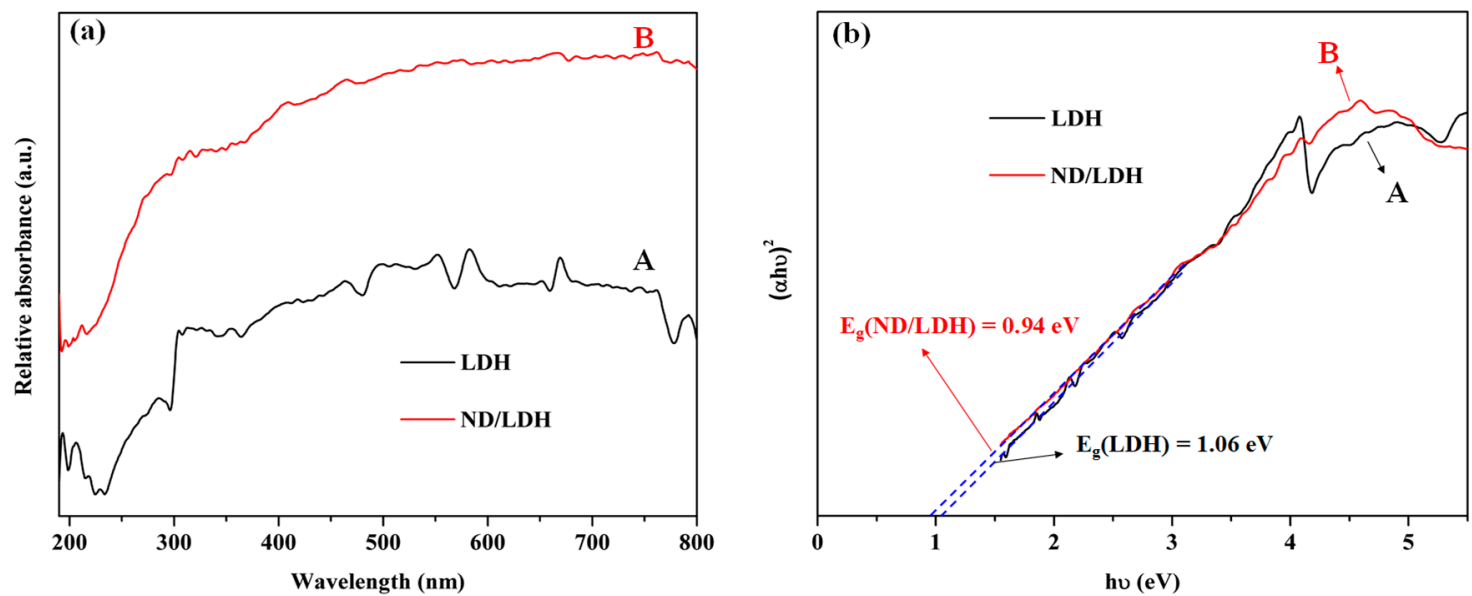

Figure 11. UV-Vis diffuse reflectance spectra (DRS) (a) and calculated the band gap ( $\left.\mathrm{E}_{\mathrm{g}}\right)(\mathbf{b})$ of LDH (A) and ND/LDH (B).

Since $E_{g}$ determines the maximum absorption wavelength of a semiconductor photocatalyst, the reducing capacity of the photogenerated electron and the oxidizing capacity of photogenerated hole are decided by the positions of conduction band (CB) and valence band (VB), respectively. In this study, the VB of LDH and ND/LDH was measured using XPS valence spectra (Figure 12) with the empirical equation from $[60,61]$. The VB maximum positions $\left(\mathrm{E}_{\mathrm{VB}}\right)$ of both $\mathrm{LDH}$ and $\mathrm{ND} / \mathrm{LDH}$ were determined to all be $1.48 \mathrm{eV}$ (vs. NHE). Subsequently, the $\mathrm{CB}$ minimum position $\left(\mathrm{E}_{\mathrm{CB}}\right)$ could be estimated by the following equation $[37,62]$ :

$$
\mathrm{E}_{\mathrm{CB}}=\mathrm{E}_{\mathrm{VB}}-\mathrm{Eg}
$$


Then, the $\mathrm{E}_{\mathrm{CB}}$ of $\mathrm{LDH}$ and $\mathrm{E}_{\mathrm{CB}}$ of $\mathrm{ND} / \mathrm{LDH}$ were calculated to be 0.42 and $0.54 \mathrm{eV}$ (vs. NHE), respectively.

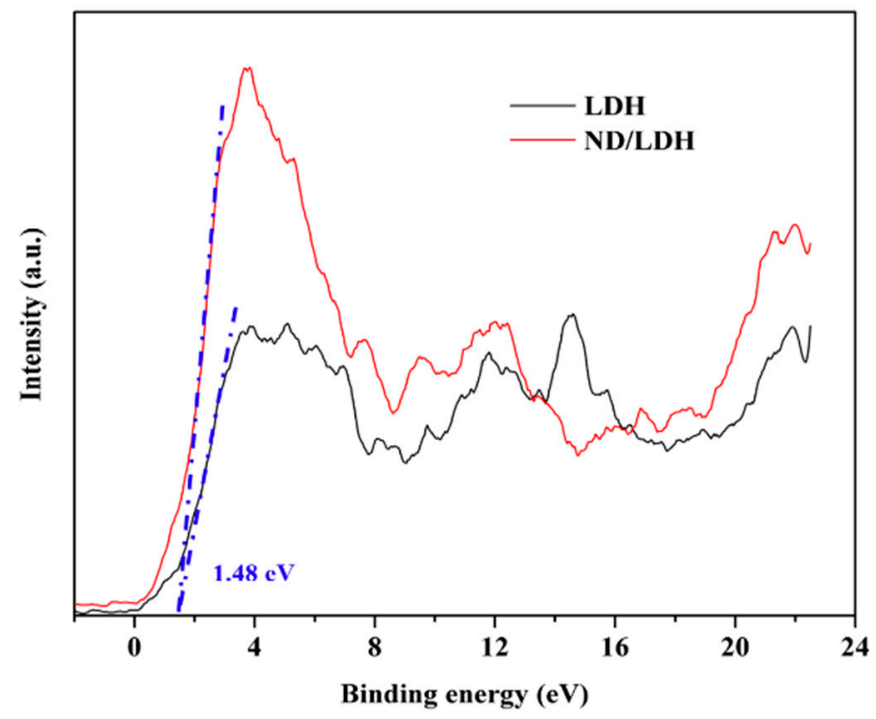

Figure 12. Valence band (VB) XPS spectra of LDH and ND/LDH.

It was known that the band gap energy of bulk diamond is $\sim 5.4 \mathrm{eV}$, and only deep UV-light can excite the valence electrons from VB to CB [58]. Moreover, because the electron diffusion lengths in a polycrystalline diamond are only on the order of $1 \mu \mathrm{m}$, many of the impinging photons are absorbed too deeply in the bulk for the resulting CB electrons to reach the surface before recombination [63]. Therefore, it is hard to utilize bulk diamond for photocatalysis directly. Fortunately, ND has a smaller particle size (typically 4-5 nm) and higher surface area (BET surface areas of around $300 \mathrm{~m}^{2} / \mathrm{g}$ ) [23-26] and exhibits a lower band gap due to the graphitized structure and the oxygen-containing groups on the surface of ND [23]. As is commonly known, the bound $\pi$ electron in sp2-hybridized carbon atoms is weak and forms a free electron when $\pi$ orbitals overlap. In this situation, the graphitized carbon atoms are bound to influence the electronic structure of ND. It has been reported that the band gap energy of ND with a fraction of sp2-hybridized carbon can be calculated by Equation (12) [64]:

$$
\frac{1}{E_{g}(x)}=\frac{1-x}{E_{g}(0)}+\frac{x}{E_{g}(1)}
$$

where $\mathrm{x}$ is the ratio of the sp2 carbon content to the amount of sp3 and sp2 carbon atoms. $\mathrm{E}_{\mathrm{g}}(\mathrm{x})$ is the corresponding band gap energy, with $\mathrm{E}_{\mathrm{g}}(0)=5.4 \mathrm{eV}$ (diamond) and $\mathrm{E}_{\mathrm{g}}(1)=1.4 \mathrm{eV}$ (graphite) [65]. It has been reported that the $\mathrm{x}$ value of detonation $\mathrm{ND}$ is $\sim 0.29$ [23]. Therefore, the calculated band gap energy of ND was $2.95 \mathrm{eV}$. It is also known that oxygen-containing groups with substantial electron density and electron-donating ability on the surface of ND will enlarge its electron affinity and lower its CB. Thus, the band gap of ND would narrow further, and has been reported to be $2.28 \mathrm{eV}$ [23]. Moreover, ND belongs to the n-type semiconductors so that the Fermi level $\left(\mathrm{E}_{\mathrm{F}}\right)$ was more closed to CB [23].

When the bare $\mathrm{LDH}$ was irradiated by visible-light, the ground state electron at VB $(\mathrm{Cu} / \mathrm{Fe} 3 \mathrm{~d}$ $t_{2 g}$ ) was excited and leapt onto $\mathrm{CB}\left(\mathrm{Cu} / \mathrm{Fe} 3 \mathrm{~d} \mathrm{e}_{\mathrm{g}}\right.$ ) (Figure 13). Because the electric potential of $\mathrm{E}_{\mathrm{VB}}$ $\left(1.48 \mathrm{eV}\right.$ vs. NHE) was lower than the electric potential of $\mathrm{E}\left(\mathrm{OH}^{-} / \mathrm{HO} \cdot\right)(1.99 \mathrm{eV}$ vs. NHE) [66,67], the photogenerated hole was unable to oxidize the $\mathrm{OH}^{-} / \mathrm{H}_{2} \mathrm{O}$ to produce strong oxidizing hydroxyl radical, consistent with the experimental fact that bare $\mathrm{LDH}$ cannot degrade $\mathrm{MB}$ dye under visible-light irradiation (Figure 6). However, the electric potential of $\mathrm{E}_{\mathrm{CB}}(0.42 \mathrm{eV}$ vs. NHE) was lower than the electric potentials of both $\mathrm{E}\left(\mathrm{Fe}^{3+} / \mathrm{Fe}^{2+}\right)\left(0.77 \mathrm{eV}\right.$ vs. NHE) and $\mathrm{E}\left(\mathrm{Cu}^{3+} / \mathrm{Cu}^{2+}\right)(2.30 \mathrm{eV}$ vs. NHE), so the photoelectrons at $\mathrm{CB}$, rather than at $\mathrm{VB}$, could more easily reduce $\mathrm{Cu}^{3+} / \mathrm{Fe}^{3+}$ into $\mathrm{Cu}^{2+} / \mathrm{Fe}^{2+}$ which 
were the key active-species for catalyzing $\mathrm{H}_{2} \mathrm{O}_{2}$-generating hydroxyl radicals for oxidative degradation of MB dye $[3,68,69]$. Therefore, the essence of visible-light driven photo-Fenton degradation of MB on bare LDH was that the excited state photoelectron can efficiently accelerate the redox cycles of $\mathrm{Cu}^{3+} / \mathrm{Cu}^{2+}$ and $\mathrm{Fe}^{3+} / \mathrm{Fe}^{2+}$. In addition, according to the metal-ligand charge transfer (MLCT) mechanism, $\mathrm{Fe}^{3+}, \mathrm{Cu}^{3+}$ or $\mathrm{Cu}^{2+}$ which is combined with hydroxyls can be photoreduced under UV-Vis light irradiation and generate hydroxyl radicals via the following reactions $[47,48,70,71]$ :

$$
\begin{aligned}
& \mathrm{Fe}(\mathrm{OH})^{2+}+\mathrm{h} \times v \rightarrow \mathrm{Fe}^{2+}+\mathrm{HO} . \\
& \mathrm{Cu}(\mathrm{OH})^{2+}+\mathrm{h} \times v \rightarrow \mathrm{Cu}^{2+}+\mathrm{HO} . \\
& \mathrm{Cu}(\mathrm{OH})^{+}+\mathrm{h} \times v \rightarrow \mathrm{Cu}^{+}+\mathrm{HO} .
\end{aligned}
$$

Since the ND and LDH were hybridized as a novel heterojunction with a common $\mathrm{E}_{\mathrm{F}}$, the photoelectrons at the $\mathrm{CB}$ of $\mathrm{LDH}\left(\mathrm{CB}_{\mathrm{LDH}}\right)$ could spontaneously migrate onto the low-energy $\mathrm{CB}$ of $\mathrm{ND}$ $\left(\mathrm{CB}_{\mathrm{ND}}\right)$, promoting the effective separation photo-induced charges. This is because ND can quickly capture the photo-generated carriers due to its rather small Bohr radius and large exciton binding energy [23]. Thus, the photoelectrons at $\mathrm{CB}_{\mathrm{ND}}$ had sufficient time to enhance the redox cycles of $\mathrm{Cu}^{3+} / \mathrm{Cu}^{2+}$ and $\mathrm{Fe}^{3+} / \mathrm{Fe}^{2+}$, further improving the photo-Fenton efficiency. Beyond that, ND can also be excited by visible-light and the photoelectron can also enhance the redox cycles of $\mathrm{Cu}^{3+} / \mathrm{Cu}^{2+}$ and $\mathrm{Fe}^{3+} / \mathrm{Fe}^{2+}$. Moreover, the photogenerated holes can oxidize $\mathrm{H}_{2} \mathrm{O}_{2}$ to produce hydroxyl radicals which was the key active-species for MB mineralization. Of course, it should be noted that dye photosensitization may be another way to degrade MB.

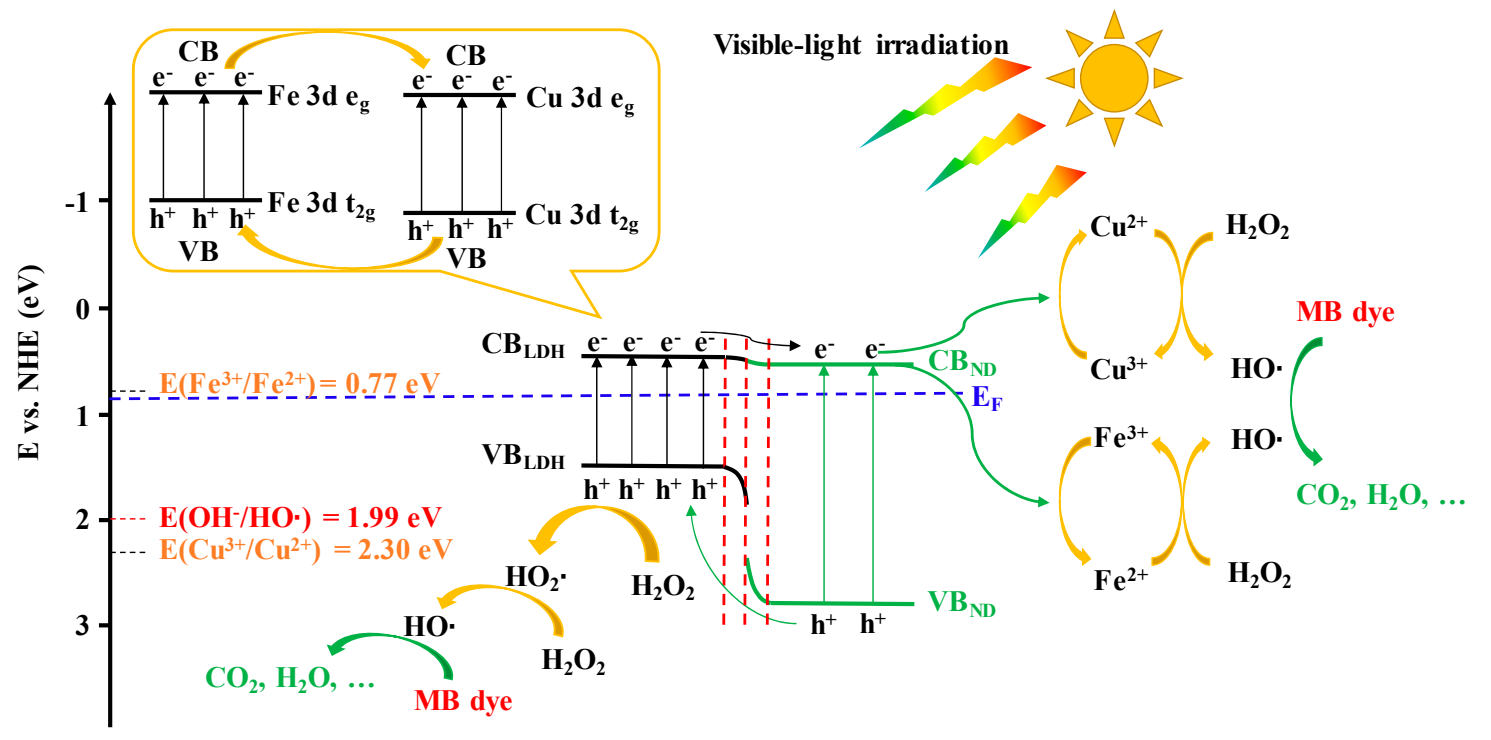

Figure 13. Proposed mechanism of the charge transfer in ND/LDH for the photo-Fenton degradation of MB dye under visible-light irradiation.

\section{Materials and methods}

\subsection{Chemicals}

$\mathrm{CuSO}_{4}(99.0 \%), \mathrm{FeCl}_{3} \cdot \times 6 \mathrm{H}_{2} \mathrm{O}(99.0 \%), \mathrm{NaOH}(99.8 \%)$, methylene blue (MB) $(99.0 \%), \mathrm{H}_{2} \mathrm{O}_{2}$ $(30.0 \%)$, absolute ethanol (EtOH) $(99.7 \%)$ and $t$-butanol (TBA) $(98 \%)$ were purchased locally from Sinopharm Chemical Reagent Co., Ltd. (Shangai, China) and were used as received without further purification. ND (detonation nanodiamond) purchased from Tianjin Qianyu super hard technology Co., Ltd. (Tianjin, China) was used in this study and the mean particle size was $\sim 5 \mathrm{~nm}$. 


\subsection{Synthesis of Powdered ND/LDH}

The powdered ND/LDH was prepared using a simple coprecipitation method. In a general procedure, $400 \mathrm{~mL}$ metal salt solution $\mathrm{A}$, containing $0.500 \mathrm{~g} \mathrm{CuSO}_{4}$ and $0.423 \mathrm{~g} \mathrm{FeCl}_{3} \cdot \times 6 \mathrm{H}_{2} \mathrm{O}(\mathrm{Cu} / \mathrm{Fe}$ molar ratio was 2:1), and $200 \mathrm{~mL} \mathrm{NaOH}$ solution $\mathrm{B}$ containing $0.0028 \mathrm{~g} \mathrm{ND}(\mathrm{pH}=9)$, were first prepared. Then, solution A was added dropwise into solution B with continuous stirring at $60^{\circ} \mathrm{C}$. It should be noted that the $\mathrm{pH}$ of solution $\mathrm{B}$ was controlled at 9 through adding concentrated $\mathrm{NaOH}$ solution $(1.0 \mathrm{M})$ from beginning to end. After that, the $\sim 600 \mathrm{~mL}$ dark-brown suspension liquid was evaporated to $\sim 60 \mathrm{~mL}$ with continuous stirring at $60{ }^{\circ} \mathrm{C}$. Subsequently, the concentrated $\sim 60 \mathrm{~mL}$ dark-brown suspension was transferred into a $100 \mathrm{~mL}$ Teflon lined stainless steel laboratory autoclave and heated in a furnace with a constant temperature of $100^{\circ} \mathrm{C}$ for a period of $10 \mathrm{~h}$. After cooling to room temperature, the dark-brown product was obtained by centrifugation at 10,000 rpm for $10 \mathrm{~min}$. Finally, this dark-brown product was dried at $80^{\circ} \mathrm{C}$ overnight, ground into fine powder with an agate mortar, and named ND/LDH. In addition, bare LDH was also synthesized as the experimental control according to above synthesis procedures, except that the $\mathrm{NaOH}$ solution $\mathrm{B}$ did not contain ND.

\subsection{Characterization of $\mathrm{ND} / \mathrm{LDH}$}

The crystal lattice structure was shown by XRD (XRD-6000 Shimadzu, Kyoto, Japan) and HRTEM (JEOL JEM2100, Tokyo, Japan). The surface elemental chemical state was characterized by XPS (ESCALAB250, Thermo Fisher Scientific, Massachusetts, USA) using monochromated Al K $\alpha$ X-ray $(1486.6 \mathrm{eV})$ as the excitation source radiation. Fourier transform infrared (FTIR) spectroscopy was conducted using the Nicolet iN 10 (Thermo Fisher) spectrometer with the resolution of $4 \mathrm{~cm}^{-1}$. The $\mathrm{N}_{2}$ adsorption-desorption isotherm was measured in a micromeritics JW-BK132F analyzer (Beijing JWGB Sci. \& Tech. Co., Ltd., Beijing, China) at $-196^{\circ} \mathrm{C}$. Brunauer-Emmett-Teller (BET) specific surface area, pore volume and pore diameter were evaluated from the adsorption branch of the nitrogen isotherm based on the BET and Barrett-Joyner-Halenda (BJH) model. UV-Vis diffuse reflectance spectra (DRS) were collected on a Shimadzu spectrophotometer (UV-2550), and $\mathrm{BaSO}_{4}$ was used as a reference.

\subsection{Photocatalytic Degradation Experiments}

The photocatalytic activity of ND/LDH was evaluated with MB. A $500 \mathrm{~W}$ Xe lamp (GXZ500, Shanghai Jiguang special lighting electric appliance factory, Shanghai, China) with an UV filter ( $420 \mathrm{~nm})$ was used as the simulated visible-light source. The distance between the lamp and the suspension was $15 \mathrm{~cm}$. Typically, $5.0 \mathrm{mg}$ of ND/LDH and $150 \mu \mathrm{L}$ of $\mathrm{H}_{2} \mathrm{O}_{2}$ were simultaneously added into an aqueous MB solution $(75 \mathrm{~mL}, 10 \mathrm{mg} / \mathrm{L})$ without initial $\mathrm{pH}$ adjustment, then illuminated under visible-light for MB photocatalytic degradation. At a certain time interval (30 min), a $3 \mathrm{~mL}$ suspension was withdrawn from the reaction and subjected to centrifugation. The MB concentration was monitored using a UV-Vis spectrophotometer (UV-1240 Shimadzu) at the wavelength of $664 \mathrm{~nm}$. In addition, catalyst dosage was optimized, catalyst stability was investigated based on catalyst reuse and metallic leaching, and total organic carbon (TOC, $\mathrm{mg} / \mathrm{L}$ ) of the MB solution was determined by a TOC analyzer (SSM-5000A Shimadzu) during the photocatalytic degradation process. To reveal the photocatalytic mechanism, typical radical scavengers such as $\mathrm{EtOH}$ and TBA were added into the photo-Fenton reactions to verify the active-species.

The degradation efficiency of MB can be defined as follows [72,73]:

$$
\text { Degradation }_{(\%)}=\left(1-\mathrm{C} / \mathrm{C}_{0}\right) \times 100 \%
$$

where $\mathrm{C}$ and $\mathrm{C}_{0}$ represent the $\mathrm{MB}$ concentration at time $\mathrm{t}$ and the initial concentration of $\mathrm{MB}$ dye, respectively. The error analysis was calculated using the following standard deviation formula [74]:

$$
\sigma^{2}=\lim _{n \rightarrow \infty}\left[\frac{1}{N} \sum\left(x_{i}-\mu\right)^{2}\right]
$$


where $\sigma$ is the standard deviation, $x_{i}$ is the observed value and $\mu$ is the mean value. The kinetics of degradation of $\mathrm{MB}$ were also investigated. The experimental data were fitted with the pseudo-first-order kinetic equation as expressed by Equation (18) [73,74]:

$$
\ln \left(\mathrm{C} / \mathrm{C}_{0}\right)=-k \times \mathrm{t}
$$

where $k$ is the apparent reaction rate constant $\left(\mathrm{min}^{-1}\right)$.

\section{Conclusions}

In this study, a simple coprecipitation method was adopted to synthesize a ND/LDH catalyst for the photo-Fenton reaction. The ND/LDH possessed a hydrotalcite-like structure, larger specific surface area and strong absorption of visible-light. The removal rate of $\mathrm{MB}$ in the ND/LDH $/ \mathrm{H}_{2} \mathrm{O}_{2}$ system under visible-light irradiation was dramatically higher than that in the $\mathrm{LDH} / \mathrm{H}_{2} \mathrm{O}_{2}$ /visible-light system. Moreover, the ND/LDH maintained good stability and photocatalytic capacity after using five times. For bare $\mathrm{LDH}$, the $\mathrm{E}_{\mathrm{VB}}$ was lower than $\mathrm{E}\left(\mathrm{OH}^{-} / \mathrm{HO} \cdot\right)$ so the photogenerated hole was unable to oxidize $\mathrm{H}_{2} \mathrm{O} / \mathrm{OH}^{-}$to produce the hydroxyl radical, whereas the photogenerated electron could efficiently accelerate the redox cycles of $\mathrm{Cu}^{3+} / \mathrm{Cu}^{2+}$ and $\mathrm{Fe}^{3+} / \mathrm{Fe}^{2+}$ to promote the decomposition of $\mathrm{H}_{2} \mathrm{O}_{2}$ into hydroxyl radicals. In the heterojunction of $\mathrm{ND} / \mathrm{LDH}$, the spontaneous migration of photoelectrons from the $\mathrm{CB}_{\mathrm{LDH}}\left(\mathrm{Cu} / \mathrm{Fe} 3 \mathrm{~d} \mathrm{e}_{\mathrm{g}}\right)$ to $\mathrm{CB}_{\mathrm{ND}}$ can effectively promote the separation of photo-induced charges, resulting in excellent photocatalytic activity on $\mathrm{MB}$ degradation. In addition, the photogenerated electrons of ND and the photogenerated holes can also react with $\mathrm{H}_{2} \mathrm{O}_{2}$ directly, or indirectly, to produce hydroxyl radicals, contributed to enhancing the photo-Fenton activity.

Author Contributions: Conceptualization, Y.A. and H.L.; methodology, L.L.; investigation and validation, L.L., S.L. and H.W.; catalysts characterization, X.S., J.L. and X.C.; mechanism analysis, L.L. and Y.A.; writing-original draft, L.L.

Funding: This study was supported by National Natural Science Foundations of China (41602249), Science and Technology Development Project of Jilin Province (20160520076JH), and College Students Innovation and Entrepreneurship Training Project of Jilin University (2017A64279).

Conflicts of Interest: The authors declare no conflict of interest.

\section{References}

1. Ma, J.F.; Ding, J.F.; Yu, L.M.; Li, L.Y.; Kong, Y.; Komarneni, S. BiOCl dispersed on NiFe-LDH leads to enhanced photo-degradation of Rhodamine B dye. Appl. Clay Sci. 2015, 109, 76-82. [CrossRef]

2. An, Y.L.; Qin, X.M. Effects of sulfamethoxazole on the denitrifying process in anoxic activated sludge and the responses of denitrifying microorganisms. Water Sci. Technol. 2018, 78, 1228-1236. [CrossRef] [PubMed]

3. Ma, Y.H.; Chen, F.; Yang, Q.; Zhong, Y.; Shu, X.Y.; Yao, F.B.; Xie, T.; Li, X.M.; Wang, D.B.; Zeng, G.M. Sulfate radical induced degradation of Methyl Violet azo dye with CuFe layered doubled hydroxide as heterogeneous photoactivator of persulfate. J. Environ. Manag. 2018, 227, 406-414. [CrossRef] [PubMed]

4. Akhundi, A.; Habibi-Yangjeh, A. Graphitic carbon nitride nanosheets decorated with $\mathrm{CuCr}_{2} \mathrm{O}_{4}$ nanoparticles: Novel photocatalysts with high performances in visible light degradation of water pollutants. J. Colloid Interface Sci. 2017, 504, 697-710. [CrossRef] [PubMed]

5. Mousavi, M.; Habibi-Yangjeh, A.; Pouran, S.R. Review on magnetically separable graphitic carbon nitride-based nanocomposites as promising visible-light-driven photocatalysts. J. Mater. Sci. Mater. Electron. 2018, 29, 1719-1747. [CrossRef]

6. Jawad, A.; Lang, J.; Liao, Z.W.; Khan, A.; Ifthikar, J.; Lv, Z.N.; Long, S.J.; Chen, Z.L.; Chen, Z.Q. Activation of persulfate by $\mathrm{CuOx@Co-LDH:} \mathrm{A} \mathrm{novel} \mathrm{heterogeneous} \mathrm{system} \mathrm{for} \mathrm{contaminant} \mathrm{degradation} \mathrm{with} \mathrm{broad} \mathrm{pH}$ window and controlled leaching. Chem. Eng. J. 2018, 335, 548-559. [CrossRef]

7. Ensing, B.; Buda, F; Baerends, E.J. Fenton-like chemistry in water: Oxidation catalysis by $\mathrm{Fe}(\mathrm{III})$ and $\mathrm{H}_{2} \mathrm{O}_{2}$. J. Phys. Chem. A 2003, 107, 5722-5731. [CrossRef] 
8. Zhang, M.L.; Yao, Q.F.; Guan, W.J.; Lu, C.; Lin, J.M. Layered Double Hydroxide-Supported Carbon Dots as an Efficient Heterogeneous Fenton-Like Catalyst for Generation of Hydroxyl Radicals. J. Phys. Chem. C 2014, 118, 10441-10447. [CrossRef]

9. Santos, P.S.M.; Duarte, A.C. Fenton-like oxidation of small aromatic acids from biomass burning in water and in the absence of light: Implications for atmospheric chemistry. Chemosphere 2015, 119, 786-793. [CrossRef] [PubMed]

10. Lei, Y.; Chen, C.S.; Tu, Y.J.; Huang, Y.H.; Zhang, H. Heterogeneous Degradation of Organic Pollutants by Persulfate Activated by $\mathrm{CuO}-\mathrm{Fe}_{3} \mathrm{O}_{4}$ : Mechanism, Stability, and Effects of $\mathrm{pH}$ and Bicarbonate Ions. Environ. Sci. Technol. 2015, 49, 6838-6845. [CrossRef] [PubMed]

11. Samakchi, S.; Chaibakhsh, N.; Moradi-Shoeili, Z. Synthesis of $\mathrm{MoS}_{2} / \mathrm{MnFe}_{2} \mathrm{O}_{4}$ nanocomposite with highly efficient catalytic performance in visible light photo-Fenton-like process. J. Photochem. Photobiol. A 2018, 367, 420-428. [CrossRef]

12. Bansal, P.; Verma, A.; Talwar, S. Detoxification of real pharmaceutical wastewater by integrating photocatalysis and photo-Fenton in fixed-mode. Chem. Eng. J. 2018, 349, 838-848. [CrossRef]

13. Kulkarni, A.; Han, C.; Bhatkhande, D.; Dionysiou, D.D. Photocatalytic degradation of maleic anhydride using visible light-activated NF-codoped $\mathrm{TiO}_{2}$. Sep. Purif. Technol. 2015, 156, 1011-1018. [CrossRef]

14. Jawad, A.; Li, Y.B.; Lu, X.Y.; Chen, Z.Q.; Liu, W.D.; Yin, G.C. Controlled leaching with prolonged activity for Co-LDH supported catalyst during treatment of organic dyes using bicarbonate activation of hydrogen peroxide. J. Hazard. Mater. 2015, 289, 165-173. [CrossRef] [PubMed]

15. Fan, G.L.; Li, F.; Evans, D.G.; Duan, X. Catalytic applications of layered double hydroxides: Recent advances and perspectives. Chem. Soc. Rev. 2014, 43, 7040-7066. [CrossRef] [PubMed]

16. Nayak, S.; Mohapatra, L.; Parida, K. Visible light-driven novel g- $\mathrm{C}_{3} \mathrm{~N}_{4} / \mathrm{NiFe}-\mathrm{LDH}$ composite photocatalyst with enhanced photocatalytic activity towards water oxidation and reduction reaction. J. Mater. Chem. A 2015, 3, 18622-18635. [CrossRef]

17. Zhou, H.L.; Song, Y.X.; Liu, Y.C.; Li, H.D.; Li, W.J.; Chang, Z.D. Fabrication of CdS/Ni-Fe LDH heterostructure for improved photocatalytic hydrogen evolution from aqueous methanol solution. Int. J. Hydrogen Energy 2018, 43, 14328-14336. [CrossRef]

18. Pausova, S.; Krysa, J.; Jirkovsky, J.; Forano, C.; Mailhot, G.; Prevot, V. Insight into the photocatalytic activity of $\mathrm{ZnCr}-\mathrm{CO}_{3} \mathrm{LDH}$ and derived mixed oxides. Appl. Catal. B-Environ. 2015, 170, 25-33. [CrossRef]

19. Zhang, G.K.; Gao, Y.Y.; Zhang, Y.L.; Guo, Y.D. $\mathrm{Fe}_{2} \mathrm{O}_{3}$-Pillared Rectorite as an Efficient and Stable Fenton-Like Heterogeneous Catalyst for Photodegradation of Organic Contaminants. Environ. Sci. Technol. 2010, 44, 6384-6389. [CrossRef]

20. Xu, L.J.; Wang, J.L. Magnetic Nanoscaled $\mathrm{Fe}_{3} \mathrm{O}_{4} / \mathrm{CeO}_{2}$ Composite as an Efficient Fenton-Like Heterogeneous Catalyst for Degradation of 4-Chlorophenol. Environ. Sci. Technol. 2012, 46, 10145-10153. [CrossRef]

21. Yan, J.C.; Chen, Y.; Qian, L.B.; Gao, W.G.; Ouyang, D.; Chen, M.F. Heterogeneously catalyzed persulfate with a CuMgFe layered double hydroxide for the degradation of ethylbenzene. J. Hazard. Mater. 2017, 338, 372-380. [CrossRef]

22. Kong, L.N.; Zhang, X.T.; Wang, C.H.; Wan, F.X.; Li, L. Synergic effects of $\mathrm{Cu}_{\mathrm{x}} \mathrm{O}$ electron transfer co-catalyst and valence band edge control over $\mathrm{TiO}_{2}$ for efficient visible-light photocatalysis. Chin. J. Catal. 2017, 38, 2120-2131. [CrossRef]

23. Lin, Z.Y.; Xiao, J.; Li, L.H.; Liu, P.; Wang, C.X.; Yang, G.W. Nanodiamond-Embedded p-Type Copper(I) Oxide Nanocrystals for Broad-Spectrum Photocatalytic Hydrogen Evolution. Adv. Energy Mater. 2016, 6. [CrossRef]

24. Pastrana-Martinez, L.M.; Morales-Torres, S.; Carabineiro, S.A.C.; Buijnsters, J.G.; Faria, J.L.; Figueiredo, J.L.; Silva, A.M.T. Nanodiamond- $\mathrm{TiO}_{2}$ Composites for Heterogeneous Photocatalysis. Chempluschem 2013, 78, 801-807. [CrossRef]

25. Mochalin, V.N.; Shenderova, O.; Ho, D.; Gogotsi, Y. The properties and applications of nanodiamonds. Nat. Nanotechnol. 2012, 7, 11-23. [CrossRef] [PubMed]

26. Aramesh, M.; Fox, K.; Lau, D.W.M.; Fang, J.H.; Ostrikov, K.; Prawer, S.; Cervenka, J. Multifunctional three-dimensional nanodiamond-nanoporous alumina nanoarchitectures. Carbon 2014, 75, 452-464. [CrossRef] 
27. Sampaio, M.J.; Pastrana-Martinez, L.M.; Silva, A.M.T.; Buijnsters, J.G.; Han, C.; Silva, C.G.; Carabineiro, S.A.C.; Dionysiou, D.D.; Faria, J.L. Nanodiamond- $\mathrm{TiO}_{2}$ composites for photocatalytic degradation of microcystin-LA in aqueous solutions under simulated solar light. RSC Adv. 2015, 5, 58363-58370. [CrossRef]

28. Kim, K.D.; Dey, N.K.; Seo, H.O.; Kim, Y.D.; Lim, D.C.; Lee, M. Photocatalytic decomposition of toluene by nanodiamond-supported $\mathrm{TiO}_{2}$ prepared using atomic layer deposition. Appl. Catal. A-Gen. 2011, 408, 148-155. [CrossRef]

29. Sempere, D.; Navalon, S.; Dancikova, M.; Alvaro, M.; Garcia, H. Influence of pretreatments on commercial diamond nanoparticles on the photocatalytic activity of supported gold nanoparticles under natural Sunlight irradiation. Appl. Catal. B-Environ. 2013, 142, 259-267. [CrossRef]

30. Navalon, S.; Martin, R.; Alvaro, M.; Garcia, H. Gold on Diamond Nanoparticles as a Highly Efficient Fenton Catalyst. Angew. Chem. Int. Edit. 2010, 49, 8403-8407. [CrossRef]

31. Navalon, S.; Sempere, D.; Alvaro, M.; Garcia, H. Influence of Hydrogen Annealing on the Photocatalytic Activity of Diamond-Supported Gold Catalysts. ACS Appl. Mater Interfaces 2013, 5, 7160-7169. [CrossRef]

32. Baidakova, M.; Vul', A. New prospects and frontiers of nanodiamond clusters. J. Phys. D Appl. Phys. 2007, 40, 6300-6311. [CrossRef]

33. Shenderova, O.; Koscheev, A.; Zaripov, N.; Petrov, I.; Skryabin, Y.; Detkov, P.; Turner, S.; Van Tendeloo, G. Surface Chemistry and Properties of Ozone-Purified Detonation Nanodiamonds. J. Phys. Chem. C 2011, 115, 9827-9837. [CrossRef]

34. Huang, H.; Lu, B.Q.; Liu, Y.Y.; Wang, X.Q.; Hu, J. Synthesis of $\mathrm{LaMnO}_{3}-$ Diamond Composites and Their Photocatalytic Activity in the Degradation of Weak Acid Red C-3GN. Nano 2018, 13. [CrossRef]

35. Gao, W.; Zhao, Y.F.; Liu, J.M.; Huang, Q.W.; He, S.; Li, C.M.; Zhao, J.W.; Wei, M. Catalytic conversion of syngas to mixed alcohols over $\mathrm{CuFe}$-based catalysts derived from layered double hydroxides. Catal. Sci. Technol. 2013, 3, 1324-1332. [CrossRef]

36. Jawad, A.; Li, Y.B.; Guo, L.S.; Khan, A.; Chen, Z.Q.; Wang, J.Y.; Yang, J.K.; Liu, W.D.; Yin, G.C. Bimetallic synergistic degradation of chlorophenols by $\mathrm{CuCoO}_{x}-\mathrm{LDH}$ catalyst in bicarbonate-activated hydrogen peroxide system. RSC Adv. 2016, 6, 72643-72653. [CrossRef]

37. Boppella, R.; Choi, C.H.; Moon, J.; Kim, D.H. Spatial charge separation on strongly coupled 2D-hybrid of $\mathrm{rGO} / \mathrm{La}_{2} \mathrm{Ti}_{2} \mathrm{O}_{7} / \mathrm{NiFe}-\mathrm{LDH}$ heterostructures for highly efficient noble metal free photocatalytic hydrogen generation. Appl. Catal. B-Environ. 2018, 239, 178-186. [CrossRef]

38. Brocenschi, R.F.; Hammer, P.; Deslouis, C.; Rocha, R.C. Assessments of the Effect of Increasingly Severe Cathodic Pretreatments on the Electrochemical Activity of Polycrystalline Boron-Doped Diamond Electrodes. Anal. Chem. 2016, 88, 5363-5368. [CrossRef]

39. Lu, C.H.; Qi, L.M.; Yang, J.H.; Zhang, D.Y.; Wu, N.Z.; Ma, J.M. Simple template-free solution route for the controlled synthesis of $\mathrm{Cu}(\mathrm{OH})(2)$ and $\mathrm{CuO}$ nanostructures. J. Phys. Chem. B 2004, 108, 17825-17831. [CrossRef]

40. Chen, L.F.; Guo, P.J.; Qiao, M.H.; Yan, S.R.; Li, H.X.; Shen, W.; Xu, H.L.; Fan, K.N. Cu/SiO 2 catalysts prepared by the ammonia-evaporation method: Texture, structure, and catalytic performance in hydrogenation of dimethyl oxalate to ethylene glycol. J. Catal. 2008, 257, 172-180. [CrossRef]

41. Gervasini, A.; Manzoli, M.; Martra, G.; Ponti, A.; Ravasio, N.; Sordelli, L.; Zaccheria, F. Dependence of copper species on the nature of the support for dispersed CuO catalysts. J. Phys. Chem. B 2006, 110, 7851-7861. [CrossRef] [PubMed]

42. Marella, R.K.; Neeli, C.K.P.; Kamaraju, S.R.R.; Burri, D.R. Highly active Cu/MgO catalysts for selective dehydrogenation of benzyl alcohol into benzaldehyde using neither $\mathrm{O}_{2}$ nor $\mathrm{H}_{2}$ acceptor. Catal. Sci. Technol. 2012, 2, 1833-1838. [CrossRef]

43. Kishore, D.; Rodrigues, A.E. Liquid phase catalytic oxidation of isophorone with tert-butylhydroperoxide over $\mathrm{Cu} / \mathrm{Co} / \mathrm{Fe}-\mathrm{MgAl}$ ternary hydrotalcites. Appl. Catal. A-Gen. 2008, 345, 104-111. [CrossRef]

44. Yang, Q.; Zhong, Y.; Li, X.M.; Li, X.; Luo, K.; Wu, X.Q.; Chen, H.B.; Liu, Y.; Zeng, G.M. Adsorption-coupled reduction of bromate by $\mathrm{Fe}(\mathrm{II})-\mathrm{Al}(\mathrm{III})$ layered double hydroxide in fixed-bed column: Experimental and breakthrough curves analysis. J. Ind. Eng. Chem. 2015, 28, 54-59. [CrossRef]

45. Yu, J.G.; Liu, S.W.; Yu, H.G. Microstructures and photoactivity of mesoporous anatase hollow microspheres fabricated by fluoride-mediated self-transformation. J. Catal. 2007, 249, 59-66. [CrossRef] 
46. Chen, F.; Yang, Q.; Wang, Y.L.; Zhao, J.W.; Wang, D.; Li, X.M.; Guo, Z.; Wang, H.; Deng, Y.C.; Niu, C.G.; et al. Novel ternary heterojunction photcocatalyst of $\mathrm{Ag}$ nanoparticles and $\mathrm{g}-\mathrm{C}_{3} \mathrm{~N}_{4}$ nanosheets co-modified $\mathrm{BiVO}_{4}$ for wider spectrum visible-light photocatalytic degradation of refractory pollutant. Appl. Catal. B-Environ. 2017, 205, 133-147. [CrossRef]

47. Tang, X.X.; Liu, Y. Heterogeneous photo-Fenton degradation of methylene blue under visible irradiation by iron tetrasulphophthalocyanine immobilized layered double hydroxide at circumneutral pH. Dyes Pigment 2016, 134, 397-408. [CrossRef]

48. Kim, J.R.; Kan, E. Heterogeneous photo-Fenton oxidation of methylene blue using CdS-carbon nanotube $/ \mathrm{TiO}_{2}$ under visible light. J. Ind. Eng. Chem. 2015, 21, 644-652. [CrossRef]

49. Ghanbari, F.; Moradi, M. Application of peroxymonosulfate and its activation methods for degradation of environmental organic pollutants: Review. Chem. Eng. J. 2017, 310, 41-62. [CrossRef]

50. Anipsitakis, G.P.; Dionysiou, D.D. Radical generation by the interaction of transition metals with common oxidants. Environ. Sci. Technol. 2004, 38, 3705-3712. [CrossRef]

51. Zhang, T.; Zhu, H.B.; Croue, J.P. Production of Sulfate Radical from Peroxymonosulfate Induced by a Magnetically Separable $\mathrm{CuFe}_{2} \mathrm{O}_{4}$ Spinel in Water: Efficiency, Stability, and Mechanism. Environ. Sci. Technol. 2013, 47, 2784-2791. [CrossRef] [PubMed]

52. Galindo, C.; Jacques, P.; Kalt, A. Photodegradation of the aminoazobenzene acid orange 52 by three advanced oxidation processes: $\mathrm{UV} / \mathrm{H}_{2} \mathrm{O}_{2} \mathrm{UV} / \mathrm{TiO}_{2}$ and $\mathrm{VIS} / \mathrm{TiO}_{2}-$ Comparative mechanistic and kinetic investigations. J. Photochem. Photobiol. A 2000, 130, 35-47. [CrossRef]

53. Mohapatra, L.; Parida, K.; Satpathy, M. Molybdate/Tungstate Intercalated Oxo-Bridged Zn/Y LDH for Solar Light Induced Photodegradation of Organic Pollutants. J. Phys. Chem. C 2012, 116, 13063-13070. [CrossRef]

54. Xu, Z.P.; Zeng, H.C. Decomposition Pathways of Hydrotalcite-like Compounds $\mathrm{Mg}_{1-x} \mathrm{Al}_{x}(\mathrm{OH})_{2}\left(\mathrm{NO}_{3}\right)_{x} \cdot n \mathrm{H}_{2} \mathrm{O}$ as a Continuous Function of Nitrate Anions. Chem. Mater. 2001, 13, 4564-4572. [CrossRef]

55. Xu, Z.P.; Zeng, H.C. Ionic interactions in crystallite growth of CoMgAl-hydrotalcite-like compounds. Chem. Mater. 2001, 13, 4555-4563. [CrossRef]

56. Kustrowski, P.; Sulkowska, D.; Chmielarz, L.; Rafalska-Lasocha, A.; Dudek, B.; Dziembaj, R. Influence of thermal treatment conditions on the activity of hydrotalcite-derived $\mathrm{Mg}$ - $\mathrm{Al}$ oxides in the aldol condensation of acetone. Microporous Mesoporous Mater. 2005, 78, 11-22. [CrossRef]

57. Li, H.Y.; Li, J.; Xu, C.C.; Yang, P.; Ng, D.H.L.; Song, P.; Zuo, M. Hierarchically porous MoS 2 /CoAl-LDH/HCF with synergistic adsorption-photocatalytic performance under visible light irradiation. J. Alloy Compd. 2017, 698, 852-862. [CrossRef]

58. Yu, Q.; Li, J.; Li, H.D.; Wang, Q.L.; Cheng, S.H.; Li, L.A. Fabrication, structure, and photocatalytic activities of boron-doped $\mathrm{ZnO}$ nanorods hydrothermally grown on CVD diamond film. Chem. Phys. Lett. 2012, 539, 74-78. [CrossRef]

59. Jorge, A.B.; Martin, D.J.; Dhanoa, M.T.S.; Rahman, A.S.; Makwana, N.; Tang, J.W.; Sella, A.; Cora, F.; Firth, S.; Darr, J.A.; et al. H-2 and O-2 Evolution from Water Half-Splitting Reactions by Graphitic Carbon Nitride Materials. J. Phys. Chem. C 2013, 117, 7178-7185. [CrossRef]

60. Di, J.; Xia, J.X.; Ji, M.X.; Wang, B.; Yin, S.; Xu, H.; Chen, Z.G.; Li, H.M. Carbon Quantum Dots Induced Ultrasmall BiOI Nanosheets with Assembled Hollow Structures for Broad Spectrum Photocatalytic Activity and Mechanism Insight. Langmuir 2016, 32, 2075-2084. [CrossRef]

61. Liu, H.; Cao, W.R.; Su, Y.; Wang, Y.; Wang, X.H. Synthesis, characterization and photocatalytic performance of novel visible-light-induced Ag/BiOI. Appl. Catal. B-Environ. 2012, 111, 271-279. [CrossRef]

62. Nashim, A.; Parida, K. n- $-\mathrm{La}_{2} \mathrm{Ti}_{2} \mathrm{O}_{7} / \mathrm{p}-\mathrm{LaCrO}_{3}$ : A novel heterojunction based composite photocatalyst with enhanced photoactivity towards hydrogen production. J. Mater. Chem. A 2014, 2, 18405-18412. [CrossRef]

63. Li, S.; Bandy, J.A.; Hamers, R.J. Enhanced Photocatalytic Activity of Diamond Thin Films Using Embedded Ag Nanoparticles. ACS Appl. Mater. Interfaces 2018, 10, 5395-5403. [CrossRef] [PubMed]

64. Hu, S.L.; Guo, Y.; Dong, Y.G.; Yang, J.L.; Liu, J.; Cao, S.R. Understanding the effects of the structures on the energy gaps in carbon nanoparticles from laser synthesis. J. Mater. Chem. 2012, 22, 12053-12057. [CrossRef]

65. Terranova, M.L.; Orlanducci, S.; Rossi, M.; Tamburri, E. Nanodiamonds for field emission: Sstate of the art. Nanoscale 2015, 7, 5094-5114. [CrossRef] [PubMed] 
66. Liu, J.; Li, J.; Bing, X.M.; Ng, D.H.L.; Cui, X.L.; Ji, F.; Kionga, D.D. ZnCr-LDH/N-doped graphitic carbon-incorporated $\mathrm{g}-\mathrm{C}_{3} \mathrm{~N}_{4}$ 2D/2D nanosheet heterojunction with enhanced charge transfer for photocatalysis. Mater. Res. Bull. 2018, 102, 379-390. [CrossRef]

67. Di, G.L.; Zhu, Z.L.; Huang, Q.H.; Zhang, H.; Zhu, J.Y.; Qiu, Y.L.; Yin, D.Q.; Zhao, J.F. Targeted modulation of g- $\mathrm{C}_{3} \mathrm{~N}_{4}$ photocatalytic performance for pharmaceutical pollutants in water using ZnFe-LDH derived mixed metal oxides: Structure-activity and mechanism. Sci. Total. Environ. 2019, 650, 1112-1121. [CrossRef]

68. Gao, Y.W.; Li, S.M.; Li, Y.X.; Yao, L.Y.; Zhang, H. Accelerated photocatalytic degradation of organic pollutant over metal-organic framework MIL-53(Fe) under visible LED light mediated by persulfate. Appl. Catal. B-Environ. 2017, 202, 165-174. [CrossRef]

69. Zhang, Y.C.; Zhang, Q.; Hong, J.M. Sulfate radical degradation of acetaminophen by novel iron-copper bimetallic oxidation catalyzed by persulfate: Mechanism and degradation pathways. Appl. Surf. Sci. 2017, 422, 443-451. [CrossRef]

70. Tryba, B.; Piszcz, M.; Grzmil, B.; Pattek-Janczyk, A.; Morawski, A.W. Photodecomposition of dyes on $\mathrm{Fe}-\mathrm{C}-\mathrm{TiO}_{2}$ photocatalysts under UV radiation supported by photo-Fenton process. J. Hazard. Mater. 2009, 162, 111-119. [CrossRef]

71. Tryba, B.; Morawski, A.W.; Inagaki, M.; Toyoda, M. Mechanism of phenol decomposition on Fe-C-TiO 2 and $\mathrm{Fe}-\mathrm{TiO}_{2}$ photocatalysts via photo-Fenton process. J. Photochem. Photobiol. A Chem. 2006, 179, 224-228. [CrossRef]

72. Ramli, Z.A.C.; Asim, N.; Isahak, W.N.R.W.; Emdadi, Z.; Ahmad-Ludin, N.; Yarmo, M.A.; Sopian, K. Photocatalytic Degradation of Methylene Blue under UV Light Irradiation on Prepared Carbonaceous $\mathrm{TiO}_{2}$. Sci. World J. 2014. [CrossRef]

73. Cai, A.J.; Wang, Q.; Chang, Y.F.; Wang, X.P. Graphitic carbon nitride decorated with S,N co-doped graphene quantum dots for enhanced visible-light-driven photocatalysis. J. Alloys Compd. 2017, 692, 183-189. [CrossRef]

74. Ramar, V.; Moothattu, S.; Balasubramanian, K. Metal free, sunlight and white light based photocatalysis using carbon quantum dots from Citrus grandis: A green way to remove pollution. Sol. Energy 2018, 169, 120-127. [CrossRef] 